\title{
EL ABORTO Y LA DIGNIDAD DE LA VIDA HUMANA: ANÁLISIS CRÍTICO DE LAS PROPUESTAS DESPERSONALIZADORAS Y DESPENALIZADORAS ${ }^{1}$
}

\author{
ABORTION AND THE DIGNITY OF HUMAN LIFE: CRITICAL ANALYSIS OF \\ DEPERSONALIZING AND DECRIMINALIZING PROPOSALS
}

\author{
Por Álvaro E. Crespo ${ }^{(*)}$
}

\begin{abstract}
Resumen: El presente trabajo indaga sobre la penalización del aborto a partir del bien jurídico protegido, esto es, la vida humana. Analiza distintas posiciones éticas o de filosofía moral que, por un lado, niegan el carácter de persona al ser humano en gestación, y, por el otro, ponen el acento en la dignidad de la mujer, en los daños que produce la penalización y en la ineficacia de ésta. Tras ello señala las consecuencias necesarias (y negativas) de tales posturas: la despersonalización de la vida humana en los primeros meses del embarazo e incluso hasta el nacimiento, y la absolutización de la autonomía de la mujer en detrimento del no nacido. Se propone, frente a ello, un enfoque ético objetivista que asegure el reconocimiento de la dignidad de la vida humana durante la gestación, que evite la despersonalización a la que llevan los sostenedores de una ética subjetivista, y que justifique la penalización como la única manera de proteger eficazmente la vida humana desde la concepción, esto es, de reconocerle la misma dignidad que la de la madre. Tal posición puede basarse en los principios de la razón práctica, lo que permitirá superar la objeción conocida como "falacia naturalista".
\end{abstract}

Palabras clave: aborto, penalización, vida humana, dignidad, autonomía procreativa

Abstract: This work investigates the criminalization of abortion based on the protected legal right, that is, human life. It analyzes different ethical or moral philosophical positions that, on the one hand, deny the character of a person to the human being in gestation, and, on the other, emphasize the dignity of women, the damage caused by the penalty and the ineffectiveness of it. After that, he points out the necessary (and negative) consequences of such positions: the depersonalization of human life in the first months of pregnancy and even until birth, and the absolutization of the autonomy of women to the detriment of the unborn. Faced with this, an objectivist ethical approach is proposed that ensures the recognition of the dignity of human life during gestation, that avoids the depersonalization to which the supporters of a subjectivist ethics lead, and that justifies criminalization as the only way to effectively protect human life from conception, that is, to recognize the same dignity as that of the mother. Such a position can be based on the principles of practical reason, which will allow to overcome the objection known as the "naturalistic fallacy".

${ }^{1}$ Artículo recibido el 17 de agosto de 2020 y aprobado para su publicación el 25 de septiembre de 2020.

(*) Abogado y notario (Universidad Católica de Córdoba). Especialista en Derecho Penal (Universidad Nacional de Córdoba). Relator de la Sala Penal del Tribunal Superior de Justicia de la Provincia de Córdoba. 
Keywords: abortion, penalization, human life, dignity, procreative autonomy

$$
\text { (1) (1) } \Theta \Theta
$$

Artículo publicado bajo Licencia Creative Commons Atribución-No Comercial-Sin Derivar. (C) Universidad Católica de Córdoba

DOI http://dx.doi.org/10.22529/rfd.2020(3)02 


\section{Introducción}

"Empecé a sospechar que podía haber algo más que superstición y tinieblas en las doctrinas de la ley natural" (John Finnis)*

El objeto del presente trabajo será analizar el bien jurídico protegido por el delito de aborto, esto es, la vida humana, y, fundamentalmente, examinar si es compatible con una protección gradual e incremental que niega la entidad de persona en, al menos, la primera etapa de la gestación, e incluso hasta el mismo nacimiento.

Ese análisis, empero, se hará desde una perspectiva prejurídica, esto es, desde el punto de vista de la filosofía moral ("tesis moral" o "discusión ética") y de la filosofía del derecho ("tesis filosófico-jurídica" o "discusión ético-política").

En particular, serán objeto de estudio diversas posiciones filosóficas o éticas que, según sus sostenedores, procuran ubicarse en una posición intermedia entre aquellas que absolutizan la vida del ser humano en gestación (a las que se atribuye un indebido fundamento religioso e incurrir en la llamada "falacia naturalista") y aquellas que absolutizan la autonomía de la madre (las que se erigen en defensoras de una moral y de un Estado laicos y se consideran asépticas de todo resquicio religioso).

Como se advertirá, el problema fundamental, desde el punto de vista ético y jurídico, es el de la relevancia de esa vida humana en desarrollo frente a otros bienes jurídicos en juego, como la vida o la salud psicofísica o, en lo que interesa al objeto de este trabajo, la autonomía de la mujer. Se argumenta, en ese sentido, que la dignidad de la mujer exige que no pueda ser tomada como instrumento o medio para un fin, y que por ello no puede ser obligada a llevar adelante un embarazo no querido. Ello en el marco de la posición, cada vez más aceptada pero no por ello indiscutida, de que la vida humana debe protegerse de manera gradual. Criterio 


\section{EL ABORTO Y LA DIGNIDAD DE LA VIDA HUMANA: ANÁLISIS CRÍTICO DE LAS PROPUESTAS DESPERSONALIZADORAS Y DESPENALIZADORAS}

receptado, por ejemplo, por la Corte Interamericana de Derechos Humanos, e invocado recurrentemente por quienes impulsan la despenalización del aborto y consideran inmoral su penalización.

Sin embargo, el reconocimiento de la dignidad de la mujer lleva a preguntar qué reconocimiento o protección jurídica debe tener el ser humano no nacido con relación al ser humano nacido -la mujer- que lo lleva en su vientre ${ }^{2}$. O con otras palabras: si debe también reconocerse su dignidad como ser humano y con qué alcance, particularmente cuando se produce una colisión entre su vida y la autonomía de la madre, respecto de la cual se habla de un derecho a la autonomía procreativa3.

En esa línea de pensamiento, aquí se analizarán las posturas de filósofos del derecho como Luigi Ferrajoli4, Rodolfo Vázquez5, Alfonso Ruiz Miguel ${ }^{6}$ y Ronald Dworkin7, que justifican la despenalización del aborto desde un punto de vista ético. Si bien la posición más radical es la del primero, todas llegan a la misma conclusión: la autonomía de la mujer debe prevalecer frente a la vida del embrión o

\footnotetext{
*Citado por MASSINI-CORREAS, "Estudio preliminar a John Finnis: Teoría del derecho natural", en FINNIS, John, Estudios de Teoría del Derecho Natural, UNAM, Instituto de Investigaciones Jurídicas, México, 2017, p. XXVIII.

2 Cuestión que ni el fallo "F., A.L." de la CSJN (13/3/2012), ni el fallo "Artavia Murillo vs. Costa Rica" de la Corte IDH (28/11/2012), aclaran debidamente para discernir su verdadero alcance. De este último se extrae la idea de que "no existe un deber de protección absoluta e incondicional de la vida prenatal... sino simplemente un deber de protección gradual e incremental según el grado de desarrollo físico del niño no nacido”. La Corte IDH precisó el contenido protegido por el artículo 4.1 de la Convención. En primer término, sostuvo que el nasciturus no es titular del derecho a la vida. Para efectos de la Convención Americana, el feto no puede ser considerado sujeto de derechos. Adicionalmente, afirmó la gradualidad de protección de la vida de que está por nacer. De todos modos, debe aclararse que en el caso referido la Corte IDH se expidió acerca del problema de la fecundación in vitro y no sobre el aborto.

3 Así, Dworkin y la Corte de los EEUU en el fallo "Roe vs. Wade.

4 Jurista italiano, discípulo de Norberto Bobbio, es uno de los principales teóricos del garantismo jurídico, teoría que desarrolló inicialmente en el ámbito del Derecho penal. Profesor de Filosofía del derecho y Teoría general del derecho.

5 Filósofo y jurista mexicano. Doctor en Filosofía por la Universidad Nacional Autónoma de México (UNAM) y licenciado en Derecho por el Instituto Tecnológico Autónomo de México (ITAM). Profesor de Teoría, Metodología y Filosofía del Derecho. Fundador y miembro del consejo editorial de la revista Isonomía (de Teoría y Filosofía del Derecho).

6 Catedrático de Filosofía del Derecho en la Universidad Autónoma de Madrid.

7 Filósofo del Derecho y catedrático de Derecho constitucional. Profesor de Teoría del derecho y de Filosofía del derecho en la Universidad de Yale, en la Universidad de Oxford, en el University College London, y en la Universidad de Nueva York.
} 


\section{EL ABORTO Y LA DIGNIDAD DE LA VIDA HUMANA: ANÁLISIS CRÍTICO DE LAS PROPUESTAS DESPERSONALIZADORAS Y DESPENALIZADORAS}

feto. Y ello, según argumentan, en razón de que no es persona sino hasta que es querido como tal por la madre (voluntarismo de Ferrajoli), o hasta que desarrolla ciertos procesos psíquicos (objetivismo mínimo de Vázquez), o hasta la viabilidad y la capacidad de sentir como determinantes de la personalidad (Ruiz Miguel). Asimismo, se argumenta que la discusión (moral) del aborto debe partir del reconocimiento de la inviolabilidad de la vida humana pero no del embrión como persona, a diferencia de la madre que sí lo es y que goza de un derecho a la autonomía procreativa como derecho moral básico (Dworkin).

El punto de partida de todas esas posturas, como se verá, es la idea de una ética liberal y de un Estado laico en el que prevalece la autonomía de las personas y que impide la imposición de determinadas posiciones morales de origen religioso.

En resumen, las posturas que analizaremos indagan sobre si el embrión o el feto, en cuanto ser humano (cuestión que no discuten ${ }^{8}$ ), es "persona", esto es, sujeto de derechos, principalmente en los primeros meses de gestación, y si por ello tiene un derecho a la vida que deba ser protegido, incluso penalmente, frente a la autonomía de la mujer9. Con otras palabras, se tratará -en términos de Massini Correas ${ }^{10}$ sobre el estatuto entitativo del embrión y la solución ética a la cuestión de la legitimación del aborto provocado.

Se comenzará desde la perspectiva del derecho penal (bien jurídico protegido) y se pasará al plano de la ética o filosofía moral, en el que se efectuará el análisis crítico de las referidas concepciones despersonalizadoras que justifican la despenalización del aborto. Se esbozará una solución superadora desde la perspectiva de filosofía moral y jurídica basada en los principios de la razón práctica desde la posición de John Finnis (cuya profundización quedará para otro trabajo).

\footnotetext{
8 Dworkin, por caso, pone de resalto la inviolabilidad de la vida humana aunque la separa del concepto de persona y, por ello, privilegia la autonomía de la mujer.

9 En los ya mencionados fallos "F. A. L." de la Corte Suprema de Justicia de la Nación (13/3/2012) y "Artavia Murillo y otros c. Costa Rica" de la Corte IDH (28/11/2012), se relativiza el derecho a la vida del ser humano no nacido y se privilegia autonomía personal de la madre.

10 MASSINI CORREAS, Carlos I., "Sobre el embrión humano y la cuestión de la personalidad. Un argumento de Luigi Ferrajoli y su discusión”, en Prudentia Iuris, N ${ }^{\circ}$ 76, 2013, pp. 105/115.

Disponible en: http://bibliotecadigital.uca.edu.ar/repositorio/revistas/sobre-embrion-humanocuestion.pdf [Fecha de consulta: 20/8/2020]
} 


\section{EL ABORTO Y LA DIGNIDAD DE LA VIDA HUMANA: \\ ANÁLISIS CRÍTICO DE LAS PROPUESTAS \\ DESPERSONALIZADORAS Y DESPENALIZADORAS}

La cuestión, en definitiva, es si esa despersonalización del ser humano no nacido es compatible con el reconocimiento de la dignidad de la vida humana o si es necesaria una perspectiva diferente. La respuesta resultará esencial para tomar posición racional en la discusión relativa a la despenalización del aborto.

\section{El concepto de bien jurídico}

Bien jurídico, según su concepción clásica, es el interés jurídicamente protegido, ya sea del individuo o de la sociedad ${ }^{11}$. Un derecho penal liberal se basa en la protección de bienes jurídicos, esto es, de intereses individuales o sociales con reconocimiento constitucional. Es el llamado principio de racionalidad o lesividad ${ }^{12}$.

La noción de bien jurídico tiene una función limitante o reductora de la punibilidad, que a su vez presenta un doble sentido: como límite jurídico-político impuesto al legislador, por un lado, y como límite infranqueable del sistema punitivo estatal dirigido a los órganos de aplicación, por el otro; en ambos casos, resulta fundamental conjugar el bien jurídico en clave de derechos humanos, a los fines de brindar mayor precisión al concepto, en procura de hacerlo funcional al sistema punitivo de un Estado constitucional y democrático y de neutralizar cualquier manipulación perversa ${ }^{13}$.

Se ha efectuado la distinción entre bien jurídico en sentido político criminal, esto es, de objeto que puede reclamar protección jurídico penal, y bien jurídico en sentido dogmático, que alude a los objetos que de hecho protege el Derecho penal vigente $^{14}$. Con gran claridad Mir Puig explica: "que el Derecho penal sólo deba proteger 'bienes jurídicos' no significa que todo 'bien jurídico' haya de ser protegido penalmente, ni tampoco que todo ataque a los bienes jurídicos penalmente

${ }^{11}$ Cf. VON LISZT, Franz, Tratado de Derecho Penal, Reus, Madrid, 1916, T. 2, p. 2.

${ }^{2}$ DE LA RÚA, Jorge - Tarditti, Aída, Derecho Penal Parte General, Hammurabi, Buenos Aires, 2014, T. 1, pp. 66-70.

13 Cf. FAVAROTTO, Ricardo Silvio - Juliano, Mario Alberto, "El bien jurídico", en Temas de Derecho Penal Argentino, La Ley, Buenos Aires, 2006, p. 128/9.

${ }^{14}$ MIR PUIG, Derecho Penal Parte General, 9ª edición, B de F, Buenos Aires, 2011, p. 120. 
tutelados deba determinar la intervención del derecho penal”, pues ello se opondría a los principios de subsidariedad y carácter fragmentario del Derecho penal ${ }^{15}$. Y en este sentido Mir Puig sostiene que "si el Derecho penal de un Estado social se legitima sólo en cuanto protege a la sociedad, perderá su justificación si su intervención se demuestra inútil, por ser incapaz de servir para evitar delitos”, y que "cuando se demuestre que una determinada reacción penal es inútil para cumplir su objetivo protector, deberá desaparecer, aunque sea para dejar lugar a otra reacción penal más leve"16.

Queda así planteado, desde un punto de vista del derecho penal, el problema fundamental que tratan las posturas éticas que aquí trataremos: si el bien jurídico "vida humana en gestación" debe ser protegido penalmente, y qué relevancia tiene, a esos fines, la eficacia o ineficacia de esa protección, si es que tiene alguna.

\section{El bien jurídico "vida” y la noción de protección gradual}

Damos por sentado, como punto de partida, que el embrión es un ser humano, esto es, que hay efectivamente una vida humana. Ello parece no ser objeto de discusión, como veremos al analizar las concepciones morales ya adelantadas, aunque en ocasiones esa realidad a veces sea cuestionada incluso desde una pretendida posición científica ${ }^{17}$.

15 MIR PUIG, obra citada, p. 120.

16 MIR PUIG, obra citada, pp. 116-117. Allí menciona que "en contra de la eficacia de la pena podrían alegarse los elevados porcentajes de reincidencia pese al cumplimiento de una pena anterior", pero a ello responde que "la eficacia de la pena no puede valorarse por esos fracasos, sino por sus posibles éxitos, y éstos han de buscarse entre los que no han delinquido y acaso lo hubieran hecho de no concurrir la amenaza de pena".

${ }^{17}$ Así sucedió, por ejemplo, en el reciente debate sobre el aborto en nuestro país desde un punto de vista pretendidamente científico Véase, en ese sentido, la exposición de Alberto Kornblihtt, doctor en Ciencias Químicas, biólogo molecular e investigador del CONICET, quien el 31 de mayo de 2018 participó a la decimoquinta jornada de debate por la legalización del Aborto en Argentina en el $15^{\circ}$ plenario de comisiones del Congreso de la Nación. Allí se manifestó a favor de la legalización del aborto, esto es, del derecho de la mujer al aborto, por considerar que el embrión no es un ser humano (desde el punto de vista científico, según alega): "el embrión o feto no son seres independientes de la mujer gestante. Sino que hasta el nacimiento son casi como un órgano de la madre"; “¿Por qué para algunos es aceptable concebir que después de la muerte legal de una persona se admite que sus células sigan vivas por un tiempo y resulta para esas mismas personas 


\section{EL ABORTO Y LA DIGNIDAD DE LA VIDA HUMANA: \\ ANÁLISIS CRÍTICO DE LAS PROPUESTAS \\ DESPERSONALIZADORAS Y DESPENALIZADORAS}

Efectuada así esta necesaria aclaración, pasemos a analizar el concepto de vida humana desde la óptica del derecho penal, esto es, como objeto de protección del delito de aborto.

El legislador argentino ha incorporado el aborto entre los delitos contra la vida de las personas previstos por el Código Penal. Se trata de uno de los bienes jurídicos fundamentales que conforman el llamado derecho penal nuclear (vida, libertad, propiedad, etcétera) ${ }^{18}$.

El aborto y el homicidio protegen el mismo bien jurídico: la vida humana. Sin embargo, se argumenta que la vida no es un fenómeno estático con un valor único e invariable, pues durante su desarrollo se ve sometida a una serie de transformaciones que inciden en su consideración social y se refleja en su diversa valoración jurídica ${ }^{19}$.

Roxin afirma que "la "vida en formación”, protegida por el § 228, ciertamente no es aún una "persona", pero a pesar de ello debe ser considerada como bien jurídico, porque la Ley Fundamental (art. 2 II 1) también protege la vida en formación como forma previa de existencia humana" (cita jurisprudencia del Tribunal Constitucional Federal). Sostiene que por esa razón "legislador puede legítimamente prohibir bajo pena el aborto", pero que una cuestión diferente es si está obligado a ello ${ }^{20}$.

Como puede verse, el penalista alemán despega el concepto de persona de la idea de titularidad de un bien jurídico. Parte así de la base de que la vida en formación (forma previa de existencia humana) es un bien jurídico protegido, pero se

difícil concebir que un embrión humano está formado por células vivas pero todavía no es un ser humano?”. Véase: https://www.telam.com.ar/notas/201806/288228-aborto-ultima-audienciadiputados.html (consultado el 29/7/2020).

${ }_{18}$ Es el llamado derecho penal de primera velocidad en términos de Silva Sánchez, basándose en el concepto de derecho penal nuclear de Hassemer, profesor de la universidad de Frankfurt. Cf. SILVA SÁNCHEZ, Jesús María, La expansión del derecho penal. Aspectos de la política criminal en las sociedades postindustriales, $2^{\mathrm{a}}$ ed., Civitas, Madrid, 2001, pp. $149 \mathrm{~s}$.

19 DONNA, Edgardo Alberto, Derecho Penal. Parte Especial, $4^{\text {a }}$ edición actualizada, RubinzalCulzoni, Santa Fe, 2001, T. I, p. 189.

${ }^{20}$ ROXIN, Derecho Penal Parte General, Civitas, Madrid, 1997, $2^{\circ}$ Reimpresión, Thomson Reuters, Buenos Aires, 2015, T. I, p. 59, § 59, Nro. 20. 


\section{EL ABORTO Y LA DIGNIDAD DE LA VIDA HUMANA: \\ ANÁLISIS CRÍTICO DE LAS PROPUESTAS \\ DESPERSONALIZADORAS Y DESPENALIZADORAS}

pregunta si y, en su caso, con qué requisitos el legislador puede estar incluso obligado a penar una conducta lesiva de bienes jurídicos ${ }^{21}$.

En este punto, reseña que el Tribunal Constitucional Federal, "en la polémica jurídica en torno a la legislación sobre el aborto, ha declarado inconstitucional la llamada solución de los plazos (es decir, la impunidad del aborto en los tres primeros meses del embarazo) con la fundamentación de que el legislador no puede renunciar por completo a la protección mediante el Derecho penal". No obstante, menciona la polémica acerca de que la protección de la vida en formación pueda conseguirse también, o incluso mejor, con otros medios distintos de los del Derecho penal, punto en el cual destaca que el Tribunal Constitucional Federal concede al legislador la posibilidad de proteger la vida en formación por otros medios distintos de los jurídico-penales ${ }^{22}$.

Sentado pues, desde la perspectiva del derecho penal, que la vida humana es el bien jurídico protegido por el delito de aborto, surge el primer problema: cuándo es el comienzo de esa vida. Se discute, en efecto, es si la vida humana comienza con la concepción o desde la anidación del óvulo fecundado en el útero. Y en razón de la incertidumbre acerca de la existencia de un embarazo en la mujer, se propone la anidación como el punto de partida indubitable del proceso de gestación y, por ende, del proceso de aborto, lo cual implica una real y eficaz protección jurídicopenal de la persona por nacer ${ }^{23}$.

Se señala, ese sentido, que la doctrina europea entiende que el mínimo del objeto material del delito de aborto está fijado a partir de la anidación del óvulo en el útero de la madre ${ }^{24}$. Es también la noción de concepción adoptado por la Corte Interamericana de Derechos Humanos en el fallo "Artavia Murillo y otros vs. Costa Rica", dictado en el año 2011. En efecto, el citado tribunal, en esa resolución, interpreta -con base en diferentes estudios científicos en uno y otro sentido- el

\footnotetext{
${ }^{21}$ ROXIN, obra citada, p. 64, § 2, nro. 26.

22 ROXIN, obra citada, T. I, pp. 64-65, § 2, nro. 27 (cita jurisprudencia en ese sentido).

23 BUOMPADRE, Jorge Eduardo, Tratado de Derecho Penal. Parte Especial, $3{ }^{\text {a }}$ edición actualizada y ampliada, Astrea, Buenos Aires, 2009, T. I, p. 192/193).

24 BUOMPADRE, obra citada, p. 192, con cita de numerosos autores europeos.
} 


\section{EL ABORTO Y LA DIGNIDAD DE LA VIDA HUMANA: ANÁLISIS CRÍTICO DE LAS PROPUESTAS DESPERSONALIZADORAS Y DESPENALIZADORAS}

sentido en el que debe entenderse el término concepción en las disposiciones de la Convención Americana de Derechos Humanos, el que se relaciona con el concepto de persona y el de ser humano (arts. 1.2 y 4.1)25. Ello en aras de interpretar el derecho a la vida prescripto en el art. 4 de la citada convención ${ }^{26}$. Pero acá no vamos a profundizar sobre la cuestión del comienzo de la gestación (desde la fecundación o desde la anidación) por no ser relevante para el objeto del presente trabajo 27 , aunque sí lo sea para otros aspectos aquí no tratados: por ejemplo, la tipicidad de las maniobras abortivas producidas antes de la anidación, como son algunos medios anticonceptivos como el DIU, la destrucción del óvulo fecundado en el laboratorio (fecundación in vitro), la interrupción del embarazo extrauterino.

Por lo demás, se trata de una cuestión sobre la cual parece no haber unanimidad entre los propios científicos, de acuerdo a lo que surge de la recopilación de estudios tenidos en consideración por la Corte IDH en la resolución referida, que se expiden de distinta manera con respecto al comienzo de la vida humana (fecundación/anidación)28. Frente a ello, el citado tribunal considera esencial la posibilidad de desarrollo que adquiere el embrión al implantarse, de la que carece absolutamente antes de ese momento. Pero la existencia de una célula diferente con información genética propia es un dato científico irrefutable, y así lo reconoce la Corte Interamericana en el fallo ${ }^{29}$.

25 'La Corte observa que el concepto de 'persona' es un término jurídico que se analiza en muchos de los sistemas jurídicos internos de los Estados Parte. Sin embargo, para efectos de la interpretación del artículo 4.1, la definición de persona está anclada a las menciones que se hacen en el tratado respecto a la 'concepción' y al 'ser humano', términos cuyo alcance debe valorarse a partir de la literatura científica”.

${ }^{26}$ Artículo 4. Derecho a la Vida. 1. Toda persona tiene derecho a que se respete su vida. Este derecho estará protegido por la ley y, en general, a partir del momento de la concepción. Nadie puede ser privado de la vida arbitrariamente.

27 En el mismo sentido lo entiende RUIZ MIGUEL, Alfonso, "El aborto, entre la ética y el Derecho", en Telos, Revista Iberoamericana de Estudios Utilitaristas, 2002, XI/2, p. 107.

${ }^{28}$ Párrafos 180 y ss. del fallo citado.

29 Una negación de esa realidad por el legislador o por los jueces haría aplicables las palabras del reconocido genetista francés Jérôme Lejeune: "Si una ley está mal fundada, hasta el punto de declarar que el embrión humano no es un ser humano, y que su Majestad la reina de Inglaterra no fue más que un chimpancé durante los 14 primeros días de existencia, esa ley no es una ley, sino una manipulación de la opinión. Nadie está obligado a aceptar la ciencia. Alguno podría decir: 'Bien, 
Ahora bien, en lo que concierne al tema aquí examinado, el fallo de la Corte IDH va más allá de esa discusión acerca del comienzo de la vida humana, al afirmar que "no es procedente otorgar el estatus de persona al embrión" (párr. 223). Y a esa conclusión llega tras una interpretación del sistema interamericano de derechos humanos (Convención Americana y Declaración Americana de los Derechos y Deberes del Hombre), el sistema universal de derechos humanos (DUDH, PIDCP, CEDAW, CDN), el sistema europeo de derechos humanos (CEDH), el sistema africano de derechos humanos. Lo que denomina "intepretación sistemática e histórica"30. También, en la misma dirección, realiza una interpretación "evolutiva", lo que tuvo en consideración "los desarrollos pertinentes en el derecho internacional y comparado respecto al status legal del embrión”, y "las regulaciones y prácticas del derecho comparado en relación con la FIV" (fecundación in vitro) ${ }^{31}$. En definitiva, con esos métodos interpretativos la Corte IDH llegó a las siguientes conclusiones: a) el embrión no puede ser entendido como persona para efectos del artículo 4.1 de la Convención Americana; b) la "concepción" en el sentido del artículo 4.1 tiene lugar desde el momento en que el embrión se implanta en el útero, razón por la cual antes de este evento no habría lugar a la aplicación del artículo 4 de la Convención; c) de las palabras "en general" se colige que la protección del derecho a la vida no es absoluta, sino es gradual e incremental según su desarrollo, debido a que no constituye un deber absoluto e incondicional, sino que implica entender la procedencia de excepciones a la regla general ${ }^{32}$.

Por otro lado, desde la doctrina penal se sostiene que el tratamiento jurídico penal de la vida humana es diferente según se trate de un ser humano nacido o no nacido: la fuerza de la protección, reflejada en la pena, es menor hasta el nacimiento y

preferimos ser ignorantes, rechazamos totalmente cualquier descubrimiento científico'. Ciertamente, es un punto de vista. Yo diría que es un punto de vista 'políticamente correcto' en determinados países, pero que es un punto de vita oscurantista, y a la ciencia le repugna el oscurantismo" (Lejeune, "Child, Family, State: Scientific Progress and Human Rights", Discurso en la conferencia de Bulevardi Foorum, Helsinki, abril de 1990, citado por Havard, Alexandre, Liderazgo virtuoso, Ediciones Palabra, Madrid, 2010).

30 Párrafos 191 a 244.

${ }^{31}$ Párrafos 245 a 264.

32 Párrafo 264. 
mayor desde este último hasta la muerte33. Por ello se dice que el nacimiento constituye un hecho relevante para la valoración social y jurídica de la vida humana: el ser humano adquiere independencia de la madre que lo gestó y comienza el proceso de socialización, su incorporación a la comunidad, lo que en el ámbito jurídico se evidencia al serle atribuida la calidad de persona, con la capacidad de ser titular de derechos y obligaciones 34 .

Esa gradualidad, entonces, implica que el ser humano en gestación tiene una protección jurídica de menor a mayor intensidad según su desarrollo. Y en las posturas de filosofía moral que trataremos ello significa que, si ese desarrollo es incipiente, prevalece la autonomía de la madre (dignidad de la mujer), y que si es avanzado la autonomía de la mujer deja de prevalecer y otras razones serán las que permitirán el aborto sin sanción penal (indicaciones)35. Pero ċes eso aceptable sin violar la dignidad de toda vida humana? He aquí planteado, pues, el núcleo central de presente trabajo, lo que trataremos a continuación.

\section{Vida humana y persona: propuestas despersonalizadoras desde la filosofía moral y la filosofía del derecho}

Trataremos aquí las propuestas de despenalización del aborto provenientes del ámbito de la filosofía moral o ética y de la filosofía del derecho, basadas en la despersonalización de la vida humana inicial.

En particular, nos detendremos -como ya se ha adelantado- en la concepción sostenida por diversos autores, como Ferrajoli, Rodolfo Vázquez, Alfonso Ruiz Miguel y Ronald Dworkin, sobre el concepto de vida humana y de persona y la naturaleza del embrión y del feto. Pues las ideas que ellos exponen sobre el

33 DONNA, obra citada, p 185.

34 DONNA, obra citada, p 190.

35 Entre los juristas argentinos algunos van en esa dirección puede mencionarse, entre otros, a Aída Kemelmajer de Carlucci, exmiembro de la Corte Suprema de Justicia de Mendoza, protagonista junto a muchas otras voces en uno y otro sentido- de las recientes discusiones jurídicas sobre el aborto en nuestro país. Cf. KEMMELMAJER de Carlucci, Aída, "Legalización del aborto y derecho a la vida. Consideraciones jurídicas", en Semanario Jurídico, Número 2189, 31/1/2019, Cuadernillo 2, Tomo 119, Año 2019 - A, p. 145. 
EL ABORTO Y LA DIGNIDAD DE LA VIDA HUMANA:

ANÁLISIS CRÍTICO DE LAS PROPUESTAS

DESPERSONALIZADORAS Y DESPENALIZADORAS

concepto de persona y de la autonomía y dignidad de la mujer definen el núcleo de la postura de los sectores que promueven despenalización del aborto36.

En contraposición al reconocimiento de la dignidad de la mujer, los autores que aquí trataremos señalan la ausencia de personalidad del no nacido. A la postre, coinciden básicamente la posición de la sentencia del Tribunal Supremo de los Estados Unidos "Roe vs. Wade" del año 1973. Tales posturas permiten, en definitiva, justificar cualquier sistema de despenalización del aborto, tanto el del plazo, que permite a la mujer abortar libremente durante el primer período del embarazo (en general los tres primeros meses), como el de las indicaciones (terapéutica, ética o criminológica, eugenésica o por piedad, social)37.

\section{a. La tutela de la autodeterminación de la maternidad (Ferrajoli)}

Este célebre jurista italiano, defensor de lo que denomina garantismo penal, destaca dos concepciones filosóficas relacionadas con la moral, es decir, éticas: la máxima de la ética kantiana según la cual ninguna persona puede ser tratada como medio para fines ajenos, y el postulado de la ética liberal expresado mediante la

\footnotetext{
${ }_{36}$ Por ejemplo, los conceptos de dignidad de la mujer y de su autonomía son centrales en la postura adoptada por el máximo tribunal de la Nación en el fallo dictado en el año 2012 (CSJN, "F., A. L. s/ medida autosatisfactiva", F.259.XLVI, 13/3/12). Posición jurisprudencial que no tenía precedentes en los fallos de ese tribunal y que parece haber definido la cuestión al menos en ese ámbito y desde esa fecha hasta la actualidad sin cambios relevantes. No obstante, repárese que, en un reciente fallo, la CSJN, en la causa "Internas de la Unidad $n^{\circ} 31$ SPF y otros s/ habeas corpus, 11/2/2020", reconoce los beneficios de la seguridad social a los niños desde el embarazo -referido a la AUH de las internas presas embarazadas o con niños menores de 4 años. Ello, acaso, vaya más en consonancia con los anteriores fallos de la Corte "Tanus" (2001), "Portal de Belén" (2002) y "Sánchez, Elvira" (2007), en los que se sentó doctrina sobre el "respeto a la vida humana desde la concepción". Postura que fue dejada de lado por la Corte en "F., A. L." con su particular interpretación de la causal no punibilidad del aborto del art. 86, segundo párrafo, inciso 2, del CP (cuando "el embarazo proviene de una violación o de un atentado al pudor cometido sobre una mujer idiota o demente"), y, sobre todo, con la entronización de la autonomía de la mujer y la directiva de elaborar protocolos de abortos no punibles basados, solamente, en la invocación, por la mujer, de la causal referida.

37 La indicación terapéutica se refiere al peligro para la vida o la salud de la mujer; la indicación ética o criminológica, a la violación; la indicación eugenésica o por piedad, a los riesgos de malformaciones físicas o psíquicas en el feto; la indicación social, a los graves trastornos personales que puede derivar del nacimiento de un hijo no deseado. Cf; RUIZ MIGUEL, Alfonso, artículo cit., p. 107. Véase también BUOMPADRE, obra citada, p. 200.
} 


\section{EL ABORTO Y LA DIGNIDAD DE LA VIDA HUMANA: \\ ANÁLISIS CRÍTICO DE LAS PROPUESTAS \\ DESPERSONALIZADORAS Y DESPENALIZADORAS}

máxima según la cual cada uno es soberano de su propio cuerpo y de su propia mente (John Stuart Mill) 38 .

Con base en ellas construye la posición moral que deriva en la despenalización del aborto: a) es verdad que el embrión es una potencialidad de persona; b) no obstante, "persona" es un término del lenguaje moral que no designa simplemente una entidad vital sino el ser nacido; c) únicamente es inviolable y merecedor de tutela como "sujeto jurídico" el embrión destinado por la madre a nacer porque ha sido concebido por ella como "persona". Tales afirmaciones son desarrolladas por el autor en calidad de tesis morales, Es decir, su argumentación discurre, en primer término, en el plano moral.

A su vez, completa el cuadro anterior con lo que considera una tesis específicamente filosófico-jurídica: la punición del aborto -sostiene- resulta lesiva de la dignidad de la mujer.

Por estas razones, considera moralmente ilegítima la punición del aborto.

Finalmente, agrega que la punición es completamente ineficaz para la propia tutela de los fetos. La denomina tesis ético-política, que equivale al principio de que una auténtica moral no precisa del apoyo del derecho (principio propio de toda metaética laica)39.

Desde esa distinción, afirma que el embrión es una entidad vital que consiste en una potencialidad de ser humano (lenguaje biológico), y que ello es un juicio de hecho del cual se puede predicar verdad o falsedad. Pero niega que de ello pueda derivarse que el embrión sea persona, porque este es un juicio de valor, y por tal, ni verdadero ni falso, sometido a la valoración moral y libertad de conciencia de cada uno. De modo que afirmar que el embrión es persona es una falacia naturalista (non sequitur): del ser se deriva el deber ser; de un juicio de hecho, un juicio de valor; de una aserción, una prescripción ${ }^{40}$.

\footnotetext{
${ }_{38}$ FERRAJOLI, Principia iuris. Teoría del Derecho y de la Democracia, 1. Teoría del Derecho, Trotta, Madrid, 2013, p. 334.

39 FERRAJOLI, obra citada, pp. 337/338.

40 La falacia naturalista es también conocida como "ley de Hume", según la cual no es posible derivar conclusiones morales o valorativas de premisas no morales o no valorativas. El término 
Lo único indiscutido, en su concepción, es que una persona, jurídica y moralmente, existe sólo en el momento del nacimiento, lo que requiere la gestación y el parto de una mujer 41 .

Y aquí reside entonces la tesis moral que propone: la mujer es quien decide la naturaleza de futura persona del embrión, esto es, se trata de una decisión que depende de su autonomía moral. Con otras palabras, la madre lo concibe como persona, en un acto de naturaleza moral y no sólo biológica. Por ello no considera moralmente aceptable que la madre, que es indudablemente persona, sea obligada a una gestación y un parto no queridos (maternidad impuesta e involuntaria). Es lo que deriva de las máximas de la ética kantiana y de la ética liberal arriba referidas: nadie puede ser tratado como medio para fines ajenos, y cada uno es soberano de su propio cuerpo y de su propia mente ${ }^{42}$.

Por ello afirma que el embrión es "inviolable" en cuanto pensado y querido como futura persona por la madre; por el contrario, si la mujer decide no concebir y, por tanto, no hacer nacer a ninguna persona, no es inviolable lo que es simplemente un embrión no destinado a nacer como persona. De modo que en su criterio tanto el concepto de persona como el de procreación son conceptos morales: designan un fenómeno biológico pero también un acto moral de voluntad43.

Ahora bien, acepta Ferrajoli que se trata de una concepción moral que no todos comparten, pero afirma que es tan legítima como la que ve en el embrión a una persona, sin que de ninguna de las dos pueda predicarse verdad o falsedad (aunque aclara que considera más razonable la que él postula). Al tratarse de dos posiciones morales incompatibles, afirma que sólo resta la recíproca tolerancia, lo que significa reconocer que ambas son posiciones morales legítimas, sin que pueda calificarse como inmoral a quien no comparta una de ellas. Pero quienes pretenden

"falacia naturalista" ha sido usado por George Edward Moore en su libro Principia Ethica, publicado en 1903, y constituye un fuerte ataque al naturalismo ético. Ha sido adoptado por todos quienes procuran refutar las concepciones objetivistas de la ética.

${ }^{41}$ FERRAJOLI, obra citada, p. 333.

${ }^{42}$ FERRAJOLI, obra citada, p. 334.

43 FERRAJOLI, obra citada, p. 335. 


\section{EL ABORTO Y LA DIGNIDAD DE LA VIDA HUMANA: \\ ANÁLISIS CRÍTICO DE LAS PROPUESTAS \\ DESPERSONALIZADORAS Y DESPENALIZADORAS}

la penalización -denuncia- pretenden imponer su moral y obligar a las mujeres a sufrir sus consecuencias44.

Y este es, precisamente, el punto en el que pasa al plano jurídico. Éste consiste, según surge de sus palabras, en la inaceptable pretensión de imponer la postura moral (el embrión es persona) a través de la prohibición jurídico penal (aborto).

En efecto, Ferrajoli plantea la siguiente cuestión jurídica o de filosofía del derecho: si está o no justificado que el derecho confiera al embrión como tal el estatus de persona e imponga respetar dicho estatus con la sanción penal45. Es decir, si está justificada la penalización del aborto.

Y a su modo de ver, la única finalidad de la penalización es afirmar una concreta moral, esto es, consagrar jurídicamente el principio moral de que el feto es persona y que eliminarlo es un ilícito moral, lo que se da de bruces con la libertad individual que fundamenta la cultura jurídica moderna, y con la autonomía de la conciencia en que se basa la moral laica ${ }^{46}$.

Y a ello agrega otras razones complementarias: la despenalización de la “interrupción voluntaria del embarazo" produce una drástica caída del número de abortos (ejemplifica con el caso de Italia y la ley del año 1978), esto es, la penalización carece de eficacia disuasoria. De modo que considera moralmente inaceptable que el principio moral perseguido por la penalización (intangibilidad de los embriones) prevalezca sobre toda otra consideración de orden práctico o moral: la carencia de eficacia disuasoria, por un lado, y la vulneración de la dignidad de la mujer, por el otro, ya que pone en peligro la vida de millones de mujeres, además de los trastornos existenciales y las humillaciones 47 .

Entiende el derecho al aborto no sólo como una libertad positiva (derecho a abortar) sino como una libertad negativa (derecho de la mujer a no convertirse en madre contra su voluntad). De modo que la prohibición penal impone a la mujer una multiplicidad de obligaciones de hacer (llevar adelante un embarazo, parir con

44 FERRAJOLI, obra citada, p. 335.

45 FERRAJOLI, obra citada, p. 336

${ }^{46}$ FERRAJOLI, obra citada, p. 336.

47 FERRAJOLI, obra citada, p. 336. 


\section{EL ABORTO Y LA DIGNIDAD DE LA VIDA HUMANA: ANÁLISIS CRÍTICO DE LAS PROPUESTAS DESPERSONALIZADORAS Y DESPENALIZADORAS}

dolor, criar y mantener un hijo) y renunciar a su proyecto de vida (medio para fines ajenos). Pero señala que un derecho penal liberal no debe constreñir a un hacer ni imponer opciones de vida ni concepciones morales; sólo puede tutelar los embriones a través de una convención que respete el pluralismo moral y la posibilidad de que cada uno ejerza sus opciones morales, sin lesiones los derechos fundamentales de la persona de la mujer y su integridad, dignidad y libertad, y que fije el momento a partir del cual la tutela del embrión deja de ser una cuestión solamente de moral. Descarta las razones biológicas y propone que sea el tiempo necesario y suficiente para que la mujer pueda tomar una decisión consciente y responsable, de modo que se garantice su libertad de conciencia (autodeterminación moral) y su dignidad como persona; es decir, decidir su maternidad, concebir o no el embrión o el feto como su hijo ${ }^{48}$.

Y con esa base adopta la posición moral de la despenalización del aborto en los primeros tres meses desde la concepción, tiempo que considera suficiente para permitir a la madre tomar una decisión consciente y responsable.

Una interesante crítica a la postura de Ferrajoli es la realizada por Massini-Correas, para quien la argumentación del autor italiano tiene como consecuencia una deriva anti-humanista del pensamiento contemporáneo y la pérdida de toda racionalidad lógica49. Destaca que su posición en favor de la eticidad del aborto sugiere constantemente que la posición contraria tiene raíces meramente dogmáticas y no racionales ${ }^{50}$. Resumimos a continuación, muy apretadamente, sus distintas críticas. Señala, en primer término, que sus referencias a la denominada "falacia naturalista" desconocen todo el debate a su respecto desarrollado en las últimas décadas, incluso en el ámbito de las doctrinas iuspositivista. Y que lo mismo sucede con sus afirmaciones cerca de la separación radical entre derecho y moral y sobre el

48 FERRAJOLI, obra citada, P. 337. Ejemplifica con el plazo de tres meses desde la concepción estipulado por la ley italiana, lo que no tiene ningún significado en lo biológico -dice- sino que permite a la mujer ejercer su libertad de conciencia.

49 MASSINI-CORREAS, Carlos I., "Sobre el embrión humano y la cuestión de la personalidad. Un argumento de Luigi Ferrajoli y su discusión”, en Prudentia Iuris, $\mathrm{N}^{\circ}$ 76, 2013, pp. 105/115.

Disponible en: http://bibliotecadigital.uca.edu.ar/repositorio/revistas/sobre-embrion-humanocuestion.pdf [Fecha de consulta: 20/8/2020]

$5^{\circ}$ En este punto cita a John Finnis y su obra "Natural law theories". 


\section{EL ABORTO Y LA DIGNIDAD DE LA VIDA HUMANA: \\ ANÁLISIS CRÍTICO DE LAS PROPUESTAS \\ DESPERSONALIZADORAS Y DESPENALIZADORAS}

carácter enteramente a-valorativo de las realidades y del discurso jurídico. Con respecto a esto último, expresa que las afirmaciones acerca del carácter completamente a-valorativo del derecho se contradicen con numerosos textos del mismo autor, que afirman la presencia de instancias valorativas en el discurso y la praxis jurídica.

En segundo término, critica que Ferrajoli adhiera al no cognotivismo ético más radical, negando los valores de verdad o falsedad para las proposiciones prácticas, pero al mismo tiempo considere que su postura es incompatible con la que ve al embrión como persona independientemente de la voluntad de su madre. Esto es, que considere incompatibles dos proposiciones no susceptibles de verdad o falsead. Ello implica, dice Massini Correas, toda una revolución en la ciencia lógica, la cual supone que las proposiciones que se oponen y pueden llegar a excluirse son solo aquellas que revisten los valores de verdad y falsedad. $\mathrm{Y}$ se trata del eterno problema de los defensores del no-cognoscitivismo ético, que tras negar la categoría de verdad a las proposiciones éticas se decían a defender sus propias proposiciones morales, en razón de que el escepticismo absoluto es autorrefutatorio ${ }^{51}$.

En tercer lugar, objeta que la expresión "todo ser humano es persona" tenga un carácter meramente moral y no prescriptivo. Se trata, a su ver, de una proposición de carácter descriptivo o asertórico y no moral (ni valorativo, ni normativo, ni imperativo), sin perjuicio de que tenga una connotación moral al ser incluida en un razonamiento moral; más aún, todo razonamiento moral debe incluir alguna proposición descriptiva, so pena de caer en la llamada "falacia normativista". Una proposición descriptiva puede integrar un razonamiento moral, y debe integrarlo si quiere concluir con imperativos concretos, y continuar siendo descriptiva, no propiamente práctico- moral. De modo que la expresión arriba señalada es susceptible de verdad o falsedad.

${ }^{51}$ MASSINI-CORREAS, cit. 


\section{EL ABORTO Y LA DIGNIDAD DE LA VIDA HUMANA: ANÁLISIS CRÍTICO DE LAS PROPUESTAS DESPERSONALIZADORAS Y DESPENALIZADORAS}

En cuarto lugar, reprocha la pretensión de reducir el carácter de persona a una cualidad derivada de la mera voluntad de la madre gestante52. Esa posición desconoce la distinción entre las cualidades constitutivas de los sujetos existentes y sus atributos accidentales. El carácter constitutivo del ser humano, lo que lo determina como tal, se ha denominado, al menos desde el siglo VI por Boecio, persona o personeidad. Y esa personeidad, propiedad de todo sujeto individual de índole racional y libre, debe distinguirse de las determinaciones accidentales como edad, sexo o las diferentes relaciones que mantiene con otros sujetos. La postura de Ferrajoli, en definitiva, desconoce esta distinción fundamental, al equiparar el carácter personal-humano del embrión con una determinación de carácter adventicio, lo que resulta contraintuitivo y desconcertante.

Por último, Massini-Correas destaca las consecuencias necesarias de la postura de Ferrajoli: a) la madre tiene el poder de otorgar la personeidad al embrión-feto que está gestando, y es persona per se, sin que el autor italiano explique quién ha otorgado o atribuido la personeidad a aquella (la madre)53; b) el carácter atributivo de la personeidad tiene como consecuencia la difuminación y la eliminación de la noción de derechos humanos, los cuales dependen del hecho de que nadie tiene la prerrogativa de definir el círculo de aquellos a quienes corresponden o dejan de corresponder, y deben reconocerse para todo ser que descienda del hombre y a partir del primer momento de su existencia natural sin otros criterios adicionales; c) la postura implica un criterio discriminatorio indudable, pues significa un poder absoluto, una tiranía sin límites, de los adultos mayores, capaces y sanos, sobre los que aún no han llegado a ese estado, en particular los que se encuentran en las primeras etapas del proceso de maduración vital humana.

\footnotetext{
${ }^{2}$ Aclara Massini-Correas que ese argumento no es original de Ferrajoli sino que tiene varios antecedentes, entre otros un trabajo de Geiselher Rüpke del año 1974, que sostiene que el carácter de titular del derecho a la vida no se refiere a la vida humana en el sentido de las ciencias naturales, sino que se adquiere solo en virtud de expectativas y estimaciones sociales de valor respecto del no nacido, especialmente de las que provienen de su madre.

53 Señala Massini-Correas (ob. cit.) que Rüpke otorga esa facultad a la sociedad como un todo (postura totalitaria), mientras que Ferrajoli "guarda un silencio ominoso" al respecto.
} 
Como puede advertirse, el autor italiano incurre en una falacia que podría denominarse del "voluntarismo constitutivo", consistente en derivar de la proposición "la madre quiere que el embrión sea persona" la proposición "el embrión es persona”.

En definitiva, la concepción ética de Ferrajoli sobre el aborto, que podemos llamar voluntarista y utilitarista, y que constituye uno de los argumentos centrales de los sostenedores de la despenalización del aborto, carece de racionalidad. Y ello porque el concepto de persona y su dignidad debe derivar de algo más que la mera voluntad de la madre, ya que de lo contrario se incurre en una petición de principio. Además, porque el fundamento de la penalización del aborto debe residir en algo diferente a la mera eficacia o ineficacia de la prohibición (si el fundamento fuese solo utilitarista, muchas figuras delictivas deberían ser derogadas por ineficaces54).

El mismo Ferrajoli destaca esta objeción desarrollada por Rodolfo Vázquez: tal voluntarismo performativo o constitutivo equivaldría a concebir al feto como un ser carente de valor, y conduciría a determinar el valor moral de la persona de manera arbitraria, en cualquier momento de la gestación e incluso después del nacimiento55.

La respuesta que da el italiano a la crítica de Vázquez es que la tutela de la autodeterminación de la maternidad solamente exige que se prevea un tiempo mínimo, por ejemplo, tres meses, para decidir el eventual aborto, puramente convencional, transcurrido el cual el feto tiene valor, obviamente no revocable, de una futura persona 56 .

Sin embargo, la fortaleza de la objeción señalada merece que la desarrollemos a continuación, sin perjuicio de lo cual -según ya adelantamos- las conclusiones de ambos autores será similar: negar el carácter de persona al embrión.

54 De manera paradigmática podríamos mencionar a los delitos relacionados con la corrupción de los funcionarios públicos.

55 FERRAJOLI, obra citada, p. 383, nota 24, en la que cita a Rodolfo VÁZQUEZ, "Comentarios a las propuestas bioético-jurídicas de Luigi Ferrajoli”, en M. Carbonell y P. Salazar -eds.-, Garantismo. Estudios sobre el pensamiento jurídico de Luigi Ferrajoli, Trotta, Madrid, 2009, pp. 500-501.

${ }^{56}$ FERRAJOLI, obra citada, p. 382, nota 24. 


\section{b. La concepción meta-ética del objetivismo mínimo (Rodolfo Vázquez)}

Rodolfo Vázquez, como hemos adelantado, califica la postura del autor italiano como un voluntarismo performativo o constitutivo, y la tacha de radical. Adopta, en cambio, una postura que considera intermedia entre dos extremos.

En efecto, en las relaciones entre el derecho y la moral, cuestión fundamental de la filosofía del derecho, distingue dos posibilidades: la tesis de la vinculación y la tesis de la separación.

Explica, citando a Ferrajoli, que la primera (de la vinculación) es propia de la religión católica: si es pecado debe ser tratado como delito (en lo que respecta al tema aquí tratado, si la supresión del embrión es inmoral, entonces debe ser configurada como ilícito por el derecho). Y la segunda (de la separación) es una de las premisas básicas de un Estado liberal, que debe ser neutral con respecto a la vida moral de las personas, y se relaciona con una visión positivista del derecho (Estado constitucional de derecho) y una visión laica del Estado; en síntesis, laicidad y pluralismo, y el principio utilitarista de lesividad como criterio de justificación de lo punible57.

Vázquez refiere que, desde el punto de vista meta-ético, la primera se basa en un absolutismo moral, y la segunda en una concepción subjetivista o voluntarista. Y tras afirmar que comparte el rechazo de Ferrajoli al absolutismo moral (fanatismo, dogmatismo, arbitrariedad e irracionalidad, que hacen depender el discurso de premisas de fe o de dogmas no sujetos a criterios empíricos o racionales), sostiene que ello no importa adoptar necesariamente una meta-ética subjetivista, no cognoscitivista o voluntarista. $\mathrm{Y}$ propone un objetivismo mínimo, ajeno al

57 VÁZQUEZ, Rodolfo, "Comentarios a las propuestas bioético-jurídicas de Luigi Ferrajoli”, en Garantismo. Estudios sobre el pensamiento jurídico de Luigi Ferrajoli, Edición de Miguel Carbonell y Pedro Salazar, Editorial Trotta, Instituto de Investigaciones Jurídicas - UNAM, Madrid, 2005, p. 494. 


\section{EL ABORTO Y LA DIGNIDAD DE LA VIDA HUMANA: \\ ANÁLISIS CRÍTICO DE LAS PROPUESTAS \\ DESPERSONALIZADORAS Y DESPENALIZADORAS}

dogmatismo, anclado en premisas empírico-racionales, de raíz liberal hobbesianakantiana 58 .

Desde la tradición hobbesiana considera posible explicar las normas morales y jurídicas a partir de la existencia de ciertas circunstancias de la vida del hombre en sociedad: necesidades primarias (biológicas o psicológicas), contenido mínimo de derecho natural, bienes básicos, convenciones profundas, o como se lo denomine. Y en este punto menciona la suposición, empíricamente verificable, de que la no satisfacción de las necesidades básicas afecta a interese vitales de los hombres.

Y desde la tradición kantiana destaca los rasgos formales y principios sustantivos que garantizan el punto de vista moral o la imparcialidad en todo discurso deliberativo: la racionalidad, generalidad y objetividad entre los primeros; la autonomía moral principalmente entre los segundos59.

Como se advierte, Vázquez asume los mismos postulados: la propuesta de una ética liberal y la defensa de un Estado laico ${ }^{60}$. Pero objeta el posible exceso al que lleva la concepción voluntarista de Ferrajoli, según la cual no hay persona sin el acto de autodeterminación de la maternidad. La considera una versión exagerada de la posición laica liberal, según la cual (i) se descarta que la vida del feto tenga valor por propiedades distintivas que lo hagan sobresalir de los animales con sensibilidad desarrollada; (ii) se concibe al aborto como cualquier otro medio de control natal que, desde una perspectiva utilitarista, se justificaría por el grave problema de la población; (iii) se desestima toda diferencia entre el feto y el recién nacido en cuanto autonomía y autoconciencia, por lo que se justificaría en ciertas circunstancias el infanticidio ${ }^{61}$.

Comparte no obstante con Ferrajoli que del hecho de que exista una vida humana (juicio de hecho) es imposible derivar la tesis moral de la calidad de persona (juicio de valor); es decir, que no se puede avanzar en la consideración de la persona moral

${ }^{8}$ VÁZQUEZ, Rodolfo, obra citada, pp. 494/495.

59 VÁZQUEZ, Rodolfo, obra citada, p. 495.

6o VÁZQUEZ, Rodolfo, obra citada, p. 496.

${ }^{61}$ VÁZQUEZ, Rodolfo, obra citada, p. 501. 


\section{EL ABORTO Y LA DIGNIDAD DE LA VIDA HUMANA: ANÁLISIS CRÍTICO DE LAS PROPUESTAS DESPERSONALIZADORAS Y DESPENALIZADORAS}

apelando exclusivamente a sus propiedades biológicas (noción biológica de persona) ${ }^{62}$.

Y adopta lo que considera una posición moderada 63 según la cual la moralidad del aborto depende de la etapa del embarazo y las circunstancias en las que se realiza. Menciona así dos opciones para determinar si el feto tiene un valor moral intrínseco que lleve a respetar su vida, y a reconocerle derechos que estén por encima del derecho de la mujer a decidir sobre su cuerpo y sobre su vida personal: la noción potencial de persona, y la noción metafísica descriptivista.

En cuanto a la primera (noción potencial de persona), niega que las propiedades potenciales del feto, por sí mismas, tengan valor moral; sólo en una etapa posterior, más desarrollado, puede adquirir propiedades, además de las biológicas, de las que pueda derivarse un valor moral.

En cuanto a la segunda (noción metafísica descriptiva) ${ }^{64}$, menciona las personas tienen tanto propiedades corpóreas como estados de conciencia, procesos mentales, propiedades psicológicas ${ }^{65}$, que no existen en los primeros meses de gestación, al no tener desarrollo del sistema neurológico necesario para desarrollar una psique. Por lo cual el feto o embrión carece de valor como individuo en esos primeros meses. Con otras palabras, no tiene propiedades psicológicas que impongan exigencias morales específicas, de tal modo que pueda hablarse de una persona moral 66 .

$\mathrm{Y}$ es aquí donde la postura central de ambos autores coincide, pues concluye Vázquez, citando a Nino, que la autonomía de la persona lleva a que no deba necesariamente protegerse al embrión o feto en los primeros meses de vida. ${ }^{67}$

62 VÁZQUEZ, Rodolfo, obra citada, p. 498.

63 VÁZQUEZ, Rodolfo, obra citada, p. 501. Cita en este punto a Manuel Atienza, "Investigación con embriones y clonación: la ética de la razonabilidad”, Revista Mexicana de Bioética.

64 En este punto se basa en: Strawson, Peter, Individuals. An Essay in Descriptive Metaphysics, Methuen and Co., London, 1959, cap. 3.

65 En este punto efectúa la siguiente cita: "si algo es capaz de tener deseos, de hacer planes para su futuro, de tener intereses, esa capacidad no permite verlo (...) como moralmente digno de consideración y respeto" (Valdés, Margarita, "El problema del aborto. Tres enfoques", en R. VÁZQUEZ [comp.], Bioética y derecho, FCE-ITAM, México, 1999, p. 133)

66 VÁZQUEZ, Rodolfo, obra citada, p. 499.

${ }_{67}$ VÁZQUEZ, Rodolfo, obra citada, p. 499. 


\section{EL ABORTO Y LA DIGNIDAD DE LA VIDA HUMANA: \\ ANÁLISIS CRÍTICO DE LAS PROPUESTAS \\ DESPERSONALIZADORAS Y DESPENALIZADORAS}

En definitiva, reprocha a Ferrajoli la carencia de un criterio objetivo o centro de imputación, y la petición de principio en la que incurre: si la voluntad de la madre hace del embrión o feto un ser con autonomía moral, qué hace que la madre sea un ser con autonomía moral. Por el contrario, sostiene que son las necesidades y capacidades psicológicas las que definen objetivamente el carácter moral de la persona, y no premisas religiosas ni una metafísica abstracta ni la idea de un ser potencial; una metafísica descriptiva a partir de las capacidades psicológicas del sujeto: capacidad de elección, deseos e intereses, presencia de placer y dolor 68 .

De modo que intenta posicionarse entre la posición religiosa cristiana que apela a la santidad de la vida humana para prohibir moralmente el aborto, y la postura laica liberal basada en la autonomía y la autoconciencia, que deriva en la posibilidad de despenalizar el aborto en cualquier supuesto, sin que haya posibilidad de conflicto de derechos entre la madre y el feto en cualquier momento de la gestación. Posición radical, esta última, en la que ubica a Ferrajoli y su voluntarismo performativo69.

Pero de manera similar al jurista italiano, sostiene que el aborto es un asunto controvertido y objeto de juicios morales y religiosos divergentes, y un Estado liberal no debe adoptar una posición por una concepción determinada. La penalización del aborto significa adoptar una de las posiciones morales-religiosas, y significa la intromisión del Estado en la esfera de autonomía de las mujeres ${ }^{70}$. Más aún, considera que la penalización del aborto significa violencia contra los derechos de la mujer: el derecho a la privacidad (decisión sobre su propio cuerpo), el derecho a la autonomía (decisión de un plan de vida propio y realización), el derecho a la dignidad (preservación de la salud, de la integridad física mental), el derecho a la igualdad (evitar la discriminación sexual) ${ }^{71}$.

68 VÁZQUEZ, Rodolfo, obra citada, p. 500.

69 VÁZQUEZ, Rodolfo, obra citada, p. 500-501.

70 VÁZQUEZ, Rodolfo, obra citada, p. 502.

${ }^{71}$ VÁZQUEZ, Rodolfo, obra citada, p. 503. Con cita de Villoro, L, “¿Debe despenalizarse el aborto?, en M. Valdés (comp.), Controversias sobre el aborto, UNAM-FCE, México, 2001, p. 253). En este punto, Vázquez toma los criterios temporales de la Corte de los Estados Unidos sentados en el fallo Roe v. Wade: 1) durante el primer trimestre del embarazo el Estado no puede reglamentar el 
Y como argumento complementario ${ }^{72}$ menciona y analiza, al igual que Ferrajoli, el criterio de la eficacia de la protección penal: la prohibición penal sólo se justifica si es estrictamente imprescindible para garantizar un derecho o un bien, y no se justifica si resulta inútil o innecesaria para ese fin73.

Como surge claramente del desarrollo de la postura de ambos autores (Ferrajoli y Vázquez) a partir de fundamentos últimos idénticos (ética liberal y Estado laico, separación entre derecho y moral) se llega a idéntica conclusión: la autonomía moral de la mujer prevalece por sobre la vida humana en los primeros meses de la gestación. La discrepancia que hemos anotado no tiene consecuencias relevantes en la postura de uno y otro: la prioridad de la autonomía de la voluntad de la mujer durante esos primeros meses se justifica, en un caso, en que debe transcurrir el tiempo necesario y suficiente para que la mujer pueda tomar la decisión consciente y responsable (el voluntarismo performativo de Ferrajoli), y en el otro, en que la vida humana no ha desarrollado suficientemente los procesos mentales o propiedades psicológicas que lleven a considerar al embrión o feto como una persona moral y, por ello, digno de consideración y respeto (objetivismo mínimo de Vázquez).

Los fundamentos son los mismos e idéntica es la consecuencia última: el derecho no debe necesariamente proteger al feto o al embrión en los primeros meses de desarrollo. Y ambos comparten el fundamento complementario de la no eficacia de la prohibición penal (utilitarismo). De ambas posturas puede derivarse lo que se denomina protección gradual o incremental según la etapa del desarrollo, que Ferrajoli toma de la ley italiana (sin fundamentar las razones de ello) y Vázquez de la decisión de la Corte estadounidense en el fallo "Roe vs. Wade".

derecho de la mujer a interrumpir su embarazo; durante el segundo, puede regular razonablemente los procedimientos abortivos en defensa de la salud de la madre (derechos de la persona actual prevalecen sobre los posibles derechos de una persona potencial); durante el tercero, el Estado puede regular o prohibir el aborto, salvo peligro para la vida de la mujer (p. 502/503).

72 "Pero si aun la vía por los derechos resultara insuficiente o poco convincente, se puede intentar pro la vía de la eficacia" (VÁZQUEZ, obra citada, p. 503).

73 Transcribe cita de RUIZ MIGUEL, Alfonso, "El aborto, entre la ética y el derecho". 


\section{c. La viabilidad y la capacidad de sentir como determinantes de la personalidad: el valor del no nacido como bien potencial, gradual y no absoluto (Alfonso Ruiz Miguel)}

Análisis similar realiza el filósofo del derecho Alfonso Ruiz Miguel, quien refiere dos ámbitos de tratamiento de la cuestión: a) la discusión ética sobre el derecho a la vida del no nacido, en la que opta por la posición intermedia similar a la de Vázquez, en razón de diferencias relevantes en el estatus del no nacido en su relación con el derecho a la autonomía de la mujer; b) la discusión ético-política sobre conveniencia de la despenalización del aborto consentido por la mujer (principio de intervención mínima en materia penal y criterios relativos a la evitación de daños derivados de la prohibición)74.

$\mathrm{Al}$ analizar la primera (discusión ética, o sobre la moralidad del aborto), cuyos fundamentos principales toma de Dworkin75, intenta también colocarse en una posición intermedia de lo que denomina "choque de absolutos": por un lado, la creencia en el derecho absoluto a la vida del no nacido; por otro lado, la creencia en el derecho absoluto o ilimitado de la mujer a su propio cuerpo (aborto como éticamente aproblemático) ${ }^{76}$.

Y brinda tres motivos para rechazar el primer absoluto: 1) la no personalidad actual del embrión y del feto hasta su viabilidad (no es persona propiamente dicha sino potencial); 2) la creencia religiosa en la animación (insuflación del alma en el cuerpo al momento de la concepción; 3) la falsedad de la tesis pseudo científica, de sabor naturalista, de la aparición de un nuevo y distinto código genético, de lo que se deriva la personalidad o humaneidad (tener código genético humano no obliga a

\footnotetext{
74 RUIZ MIGUEL, Alfonso, "El aborto, entre la ética y el derecho", en Telos, Revista Iberoamericana de Estudios Utilitaristas, 2002, XI/2, pp. 105/124.

75 RUIZ MIGUEL, Alfonso, obra citada, p. 111, nota 6, y p. 118, nota 13. Menciona que su postura proviene de la expuesta por DWORKIN en su libro El dominio de la vida. Una discusión acerca del aborto, la eutanasia y la libertad individual, traducción de Ricardo Caracciolo y Víctor Ferreres, Barcelona, Ariel, 1994.

${ }^{76}$ RUIZ MIGUEL, Alfonso, obra citada, p. 111.
} 


\section{EL ABORTO Y LA DIGNIDAD DE LA VIDA HUMANA: ANÁLISIS CRÍTICO DE LAS PROPUESTAS DESPERSONALIZADORAS Y DESPENALIZADORAS}

atribuir la personalidad moral, y sí son relevantes la capacidad de consciencia o la capacidad de sentir)77.

Para este autor no existe un criterio científico que determine objetivamente la personalidad moral de los seres humanos (rechaza que sea el mero código genético ${ }^{78}$, es decir, cuándo y por qué los seres humanos merecen respeto por su dignidad. Se trata de un criterio que exige valoraciones que no dependen sólo de hechos objetivos.

Con relación al segundo absoluto (autonomía total o sin restricciones de la mujer), menciona tres críticas: 1) tanto los abortos tempranos como tardíos serían moralmente equivalentes, pero su viabilidad y la capacidad de sentir que aparecen alrededor de sexto mes de gestación demuestran que hay intereses moralmente concurrentes; 2) no habría motivo para reprochar moralmente a la mujer por las conductas imprudentes durante el embarazo que ponen en riesgo la salud del futuro niño; 3) los abortos por motivos triviales o con fines de comercialización de tejidos fetales serían moralmente tan justificables como los de una adolescente, una mujer violada, una mujer sola con varios hijos79.

En consecuencia, en este primer plano ético adopta lo que considera una propuesta intermedia o conciliadora entre las comentadas precedentemente, a las que estima inaceptables por ser absolutas y por las consecuencias referidas. Esa propuesta consiste en que es "perfectamente aceptable" la idea de que la vida de los no nacidos es valiosa moralmente, pero al mismo tiempo afirma que el valor de la vida humana potencial es variable según el grado de proximidad a la personalidad ${ }^{80}$. De modo que su concepto central es el de vida humana potencial y el de la gradualidad.

Desde esa perspectiva señala los siguientes grados: 1) el más alejado es el de los no nacidos meramente posibles o futuros, es decir, los no concebidos ni siquiera

77 RUIZ MIGUEL, Alfonso, obra citada, pp. 111/113.

78 Aquí menciona la diferencia personal entre los gemelos monocigóticos, y el caso de la combinación de dos óvulos fecundados gemelos en uno solo que da lugar a un solo individuo. Por lo que descarta que la identidad personal esté predeterminada en el cigoto por el código genético.

79 RUIZ MIGUEL, Alfonso, obra citada p. 116.

80 RUIZ MIGUEL, Alfonso, obra citada, p 117. 


\section{EL ABORTO Y LA DIGNIDAD DE LA VIDA HUMANA: ANÁLISIS CRÍTICO DE LAS PROPUESTAS DESPERSONALIZADORAS Y DESPENALIZADORAS}

mentalmente, las generaciones futuras, que tienen un valor globalizado, por el que es inaceptable el desgaste de las energías no renovables y el deterioro de medio ambiente, y justifica políticas de fomento y de limitación de la natalidad; 2) un grado más próximo a la personalidad es el de los no nacidos existentes, que merecen protección incluso penal ${ }^{81}$.

Tal protección penal será alta frente a los abortos no consentidos por la mujer, y gradual en los consentidos de acuerdo al criterio -que considera más útil y plausible- de los tres trimestres. En los dos primeros trimestres de la gestación el valor que debe reconocerse al no nacido es el de una vida humana potencial: en el primero prevalece el derecho a la intimidad y a la autonomía de la mujer, y se asimila a la libertad de anticoncepción, mientras que en el segundo se admiten regulaciones más o menos protectores porque a su término se produce la viabilidad y la capacidad cerebral de sentir. $Y$ en el tercer trimestre merece una protección equivalente a la de las personas propiamente dichas, porque el feto es viable y adquirió la capacidad referida, por lo que el aborto equivale al infanticidio ${ }^{82}$.

De modo que en los primeros seis meses de gestación no hay una protección que derive de un derecho a la vida fuerte (de un interés que sea justo o injusto desplazar), en el que rija un criterio universal y categórico de justicia o corrección. La protección deriva, en cambio, de su valor como ser humano potencial, respecto del cual rige un criterio de bondad o bien que es gradual y puede tolerar su sacrificio en caso de conflicto con otros bienes o derechos (campo de valoración de algo como bueno o malo donde opera el argumento del mal menor) ${ }^{83}$.

Y esos otros derechos son los de las mujeres en conflicto con bienes todavía no personalizados. Por ello concluye que es éticamente intolerable obligar a las mujeres a tener hijos no deseados bajo sanción penal, esto es, obligarla a parir y llevar la responsabilidad de su cuidado y educación u optar por darlo en adopción. Esto atenta contra la dignidad de las mujeres por desconsiderar su autonomía

\footnotetext{
${ }^{81}$ RUIZ MIGUEL, Alfonso, obra citada, p. 117.

82 RUIZ MIGUEL, Alfonso, obra citada, p 117/118, 119.

83 RUIZ MIGUEL, Alfonso, obra citada, p.118. Acá remite a la posición de DWORKIN.
} 


\section{EL ABORTO Y LA DIGNIDAD DE LA VIDA HUMANA: \\ ANÁLISIS CRÍTICO DE LAS PROPUESTAS \\ DESPERSONALIZADORAS Y DESPENALIZADORAS}

personal (maquinas reproductoras sin capacidad de decidir sobre su propia vida) y por discriminarlas frente a los varones (embarazo y parto las afectan sólo a ellas, y las cargas familiares son predominantemente su responsabilidad) ${ }^{84}$.

En el tercer trimestre, en cambio, la viabilidad y la capacidad de sentir del no nacido lo hacen merecedor de protección similar a la de las personas propiamente dichas. El conflicto con el derecho a la vida de la mujer será tratado como un caso de estado de necesidad.

Fijada así su postura en el plano ético pasa a la discusión ético-política (plano éticojurídico), que reside en la necesidad, conveniencia o justificación de la penalización del aborto. Señala dos razones para dar una respuesta negativa: el principio de intervención mínima del Derecho penal y la necesidad de proporción entre los daños del delito y de las penas ${ }^{85}$.

El principio de intervención mínima requiere que la sanción penal sea imprescindible para garantizar un derecho o un bien, de manera que no estará justificada cuando resulte inútil o innecesaria para esos fines. $Y$ el autor indica tres razones por las que resulta inútil el castigo penal del aborto: 1) la pena es ineficaz por los altos índices de abortos voluntarios efectivamente provocados independientemente de la regulación legal más o menos prohibitiva o permisiva de que se trate; 2) en España no es perseguible ningún delito cometido en el extranjero si la conducta no es también delictiva en el país de que se trate86; 3) el castigo penal sería imposible de generalizar por tratarse de una práctica muy extendida (calcula que el castigo de los médicos, las mujeres, los cómplices y encubridores, derivaría en una cifra de condenados superior a la población carcelaria actual 87 .

$\mathrm{Y}$ en lo que concierne a la proporción entre el daño y la pena, menciona tres tipos de daños derivados de la prohibición rígida del aborto: 1) daño en los hijos no deseados, pues no serán necesariamente aceptados en el seno familiar (aumento de

\footnotetext{
84 RUIZ MIGUEL, Alfonso, obra citada, 118.

85 RUIZ MIGUEL, Alfonso, obra citada, p. 119.

${ }^{86}$ RUIZ MIGUEL, Alfonso, obra citada, p. 120. Cita Ley Orgánica del Poder Judicial.

87 RUIZ MIGUEL, Alfonso, obra citada, p. 120.
} 


\section{EL ABORTO Y LA DIGNIDAD DE LA VIDA HUMANA: \\ ANÁLISIS CRÍTICO DE LAS PROPUESTAS \\ DESPERSONALIZADORAS Y DESPENALIZADORAS}

familias desarticuladas y del abandono de los hijos, causa de violencia y de vidas desgraciadas); 2) riesgos para la salud de las mujeres, pues la prohibición provoca una cifra importante de muertes y graves enfermedades en mujeres que realizan abortos en condiciones sanitarias inadecuadas (lo que, además, torna inconveniente alguna propuesta de castigar sólo a los médicos que practican los abortos); 3) doble desigualdad pues, por un lado, la obligación penal a parir resulta discriminatoria respecto de los hombres por desconsideración hacia la dignidad y la autonomía de la mujer, y por otro lado, resulta discriminatoria por producir efectos negativos en las mujeres con menos medios culturales y económicos para procurarse abortos seguros y legales 88 .

Concluye que las razones éticas y las de política criminal abonan la despenalización de los abortos socialmente típicos, que son los provocados por embarazos no deseados por motivos que comprometen seriamente el conjunto de la vida de la mujer. Destaca que el aborto nunca es trivial para la mujer y que puede recurrirse a muchas acciones para aliviar los problemas que subyacen al aborto y pueden ayudar a disminuir su número89, pero el uso de la ley penal sólo deja dos alternativas ante el aborto no deseado: excluir la pena y permitir la realización de abortos en condiciones sanitarias apropiadas, o exigir con amenaza penal la llegada a término del embarazo, lo que no asegura que disminuya el número de abortos sino que impide solamente que se realicen en condiciones sanitarias adecuadas ${ }^{\circ}$.

\section{d. La sacralidad e inviolabilidad de una vida humana impersonal, y el derecho moral a la autonomía procreativa (Dworkin)}

Dworkin, también desde un plano moral, intenta establecer postulados que reconciliarían las intuiciones morales básicas de la posición conservadora y la

\footnotetext{
88 RUIZ MIGUEL, Alfonso, obra citada, p. 122/123.

89 Creación de centros de planificación familiar, campañas de información sobre anticonceptivos, facilitación de medios e intervenciones médicas que garanticen la anticoncepción, ayudas sociales para madres solas, etcétera.

90 RUIZ MIGUEL, Alfonso, obra citada, pp. 123/124. 


\section{EL ABORTO Y LA DIGNIDAD DE LA VIDA HUMANA: ANÁLISIS CRÍTICO DE LAS PROPUESTAS DESPERSONALIZADORAS Y DESPENALIZADORAS}

postura liberal. El punto partida común es la sacralidad o inviolabilidad de la vida humana: el embrión, en cuanto vida humana, es algo valioso, pero no es persona, esto es, no es sujeto de derechos. Se resume en la expresión "valor impersonal de la vida humana" 91 .

Ese valor impersonal de la vida humana significa que, constitucionalmente, no tiene derechos ni intereses que invocar ni oponer frente al ejercicio de los derechos por parte de la mujer. Es el llamado "derecho a la autonomía procreativa" del fallo Roe vs. Wade, de cual se sigue el derecho al aborto92.

Ese reconocimiento del valor impersonal de la vida humana lo atribuye tanto a las religiones, en especial a la católica (o a lo que debería, a su entender, ser una posición religiosa coherente), como también, en un extremo opuesto, al movimiento feminista93. Acá no indagaremos sobre su interpretación de lo que

${ }_{91}$ DWORKIN, Ronald, El dominio de la vida. Una discusión acerca del aborto, la eutanasia y la libertad individual, traducción de Ricardo Caracciolo y Víctor Ferreres, Barcelona, Ariel, 1994, p. 55: "para la mayoría de las personas la controversia del aborto no versa sobre si el feto es una persona con derecho a la vida, sino sobre la santidad de la vida entendida de un modo más impersonal"; p. 204: "la creencia de que el valor humano de la vida trasciende el valor que tiene para la criatura que la vive - esto es, que la vida humana es impersonal y objetivamente valiosa - es una creencia religiosa, incluso cuando es sostenida por individuos que no creen en Dios".

$9^{2}$ DWORKIN, obra citada, pp. 194 y ss. Señala a ese respecto: "He distinguido dos preguntas; por una parte, si la mujer tiene derecho a una autonomía procreativa y, por otra, si los estados tienen un interés imperativo en proteger la vida humana. Nuestra discusión las ha reunido como dos aspectos de una misma cuestión. ¿̇Hay algo especial acerca de la procreación y del aborto, de tal manera que, aunque los gobiernos puedan, para proteger valores intrínsecos, regular el comportamiento de las personas, las mujeres embarazadas tengan derecho a que el Gobierno no les prohíba terminar con su embarazo?” (p. 196).

93 DWORKIN, obra citada, pp. 55-69 y 69-82, respectivamente. Desde el punto de vista religioso sostiene: "la opinión doctrinal religiosa acerca del aborto puede entenderse mejor si se la concibe como una opinión basada en el presupuesto de carácter autónomo de que la vida humana tiene valor intrínseco, en lugar de en la idea de carácter derivado de que el feto es una persona con sus propios intereses y derechos (p. 69). Desde el punto de vista del feminismo explica: "Abortar supone desperdiciar el valor intrínseco - la santidad, la inviolabilidad- de una vida humana y es por lo tanto una grave infracción moral, excepto cuando el valor intrínseco de otras vidas humanas se desperdiciara de adoptarse una decisión contraria al aborto. Cada una de las mujeres del estudio de Gilligan estaba asumiendo ese terrible conflicto y reaccionando ante él. Cada una intentaba, por encima de todo, calibrar su responsabilidad de respetar el valor intrínseco de su propia vida, situar en ese contexto la tremenda decisión que habría de tomar y considerar las decisiones acerca de si interrumpir o no una nueva vida en el marco de la exigencia más general de mostrar respeto por cualquier vida, empezando por la propia y con la responsabilidad inherente. Decidir sobre el aborto no es un problema aislado, desconectado del resto de decisiones vitales, sino más bien un ejemplo dramático y muy ilustrativo del tipo de decisiones que las personas deben tomar a lo largo de sus vidas, todas ellas reveladoras de sus convicciones acerca del valor de la vida y el significado de la muerte" (p. 82). 


\section{EL ABORTO Y LA DIGNIDAD DE LA VIDA HUMANA: ANÁLISIS CRÍTICO DE LAS PROPUESTAS DESPERSONALIZADORAS Y DESPENALIZADORAS}

debe ser una posición religiosa coherente ni la de los movimientos feministas, aunque el análisis que realiza es sumamente interesante para el que desea indagar sobre ambos puntos, se acepten o no sus conclusiones 94 .

Lo que resulta relevante es, en definitiva, su idea de que el postulado de la santidad e inviolabilidad de la vida humana es compartido por los extremos conservador y liberal. Es decir, la noción del valor intrínseco de la vida humana como principio básico compartido por todos. $\mathrm{Y}$ ese principio básico debe ser el núcleo del debate sobre el aborto, y no la discusión sobre si el embrión es o no una persona.

Desde ese punto de vista entiende que las posiciones sobre el aborto pueden sustentarse en razones de carácter autónomo y razones de carácter derivado. Las primeras referidas a la santidad e inviolabilidad de la vida humana, y las segundas, a los derechos individuales de las personas reconocidas constitucional y jurídicamente como tales.

Y toma la posición de que la cuestión de legitimidad del aborto es un asunto que afecta a convicciones referidas a valores intrínsecos y no a derechos. Es decir, a razones de carácter autónomo (inviolabilidad de la vida del embrión/feto) y no a razones de carácter derivado (embrión/feto como titular de derechos). Y por ese motivo el Estado no debe intervenir por tratarse de materia reservada a la conciencia de los individuos y, más concretamente, de la mujer95.

\footnotetext{
94 Por caso, las distintas posturas que asumió la Iglesia Católica con relación al aborto se encuentra detalladamente descripta en la obra referida, sin perjuicio de la posición que sobre ella finalmente adopta (ob cit., p. 55 a 69).

95 DWORKIN, ob. cit, pp. 22-24. Allí, por ejemplo, dice: "Los comentaristas se sorprenden a menudo por lo que interpretan como notables contradicciones en las opiniones sobre el aborto (...). Son desconcertantes, sin embargo, sólo si interpretamos las afirmaciones de los que opinan que el aborto es un asesinato, o tan malo -o casi tan malo- como un asesinato, o que la vida no nacida debe ser protegida, o que los niños no nacidos tienen «derecho» a la vida, como expresión de como dijimos anteriormente- la concepción de carácter derivado, según la cual el feto tiene derechos e intereses propios. Nadie puede sostener coherentemente que el feto tiene derecho a que no le maten y al mismo tiempo sostener que es inmoral que el Gobierno proteja ese derecho a través de la ley penal. La principal responsabilidad del Gobierno, al fin y al cabo, es proteger los intereses de cada miembro de la comunidad, especialmente los intereses de quienes no pueden protegerse por sí mismos. Pero no existe incoherencia ninguna si suponemos que las personas que condenan el aborto por ser moralmente incorrecto se basan de hecho en lo que denominamos una explicación de carácter autónomo de por qué es inmoral -es decir, de si suponemos que comparten la profunda convicción de que es intrínsecamente inmoral poner fin deliberadamente a una vida humana-. Es perfectamente coherente sostener esta idea, incluso hasta el límite, y sin embargo creer que la 


\section{EL ABORTO Y LA DIGNIDAD DE LA VIDA HUMANA: \\ ANÁLISIS CRÍTICO DE LAS PROPUESTAS \\ DESPERSONALIZADORAS Y DESPENALIZADORAS}

Por ello propone "rechazar la explicación convencional -según la cual el debate del aborto versa sobre la cuestión de si el feto tiene derechos e intereses-, y reemplazarla por la que hemos propuesto" ${ }^{96}$.

La objeción que puede hacerse a tal propuesta, siguiendo a Corral Talciani y Vigo Pacheco, es la siguiente: la existencia de derechos y garantías constitucionales y de la legislación que de ellos se deriva se justifica, únicamente, en que por medio de ellos el ordenamiento jurídico está protegiendo ciertos valores intrínsecos que el Estado y la sociedad, en su conjunto, consideran fundamentales. Es decir, las razones de carácter derivado se refieren, de modo mediato o inmediato, a razones de carácter autónomo97.

Sostienen que la apelación al vago principio del respeto a la santidad de la vida humana en general no resulta muy informativa a la hora de establecer criterios claros que limiten el ámbito dentro del cual la decisión por el aborto estará moralmente justificada. El único modo eficaz de distinguir claramente entre lo lícito y lo ilícito, lo tolerable y lo intolerable, consiste precisamente en partir del reconocimiento expreso del carácter personal de toda forma individual de vida humana, no importa cuál sea su estado de desarrollo.

Compartimos la conclusión de que la controversia sobre la legitimidad del aborto no puede superarse por la simple referencia a la libertad individual en materias de conciencia. Antes bien, eso es precisamente lo que está en discusión: si el aborto es una cuestión en la que el Estado debe abstenerse de intervenir por quedar reservada a la libertad de conciencia de los individuos. No consideran tales autores, pues, que se trate de una posición superadora de posturas basadas en una confusión en torno al verdadero alcance de la discusión, como cree Dworkin, sino que "se trata más bien de una genuina discusión de principios, en la que, hoy por

decisión de poner fin o no a una vida humana durante la primera etapa del embarazo debería dejarse a la mujer embarazada, cuya conciencia está más directamente conectada con la decisión y que es titular de los intereses en juego más importantes".

${ }_{96}^{6}$ DWORKIN, ob. cit, p. 25

97 CORRAL TALCIANI, Hernan F. - VIGO PACHECO, Alejandro Gustavo, Revista chilena de derecho, Vol. 21, $\mathrm{N}^{\circ}$ 2, 1994, pp. 431/440. 
hoy, se expresan concepciones radicalmente diferentes y, en lo esencial, irreconciliables, acerca del tratamiento que una sociedad democrática y respetuosa 'en serio' de la vida y los derechos individuales ha de concederle a toda forma de vida humana"98.

\section{Los principios de la razón práctica como propuesta superadora: del subjetivismo al objetivismo ético (John Finnis)}

Como surge de las concepciones morales hasta aquí descriptas y de las críticas realizadas, el debate en el plano ético es el que principalmente, o en primer término, interesa al derecho penal y es necesario discernir correctamente. La discusión en los ámbitos filosófico-jurídico y ético-político sobre la conveniencia de penalizar el aborto dependerá, en gran medida, de la conclusión a la que se arribe en el primero.

En efecto, si se acepta que en la primera etapa de la gestación el ser humano no es persona, que para serlo depende de la voluntad de la madre, o que lo determinante es la viabilidad y el desarrollo de procesos mentales y de capacidad de sentir, de modo que solo a los seis meses pueda ser considerado equivalente a una persona propiamente dicha, entonces la autonomía de la mujer prevalecerá absolutamente, y en cualquier caso, hasta el nacimiento o al menos en los primeros meses del embarazo, y las consecuencias negativas de la penalización serán concluyentes para la despenalización.

En cambio, si en el plano ético se puede sostener, con argumentos plausibles, que el valor de la vida humana, esto es, la dignidad que la hacen merecedora de la protección, se origina en algo diferente a la voluntad de la madre o a la viabilidad y desarrollo de facultades mentales, entonces los inconvenientes de la penalización no tendrían la relevancia que tales autores propugnan, sin que ello implique

98 Ibidem. 


\section{EL ABORTO Y LA DIGNIDAD DE LA VIDA HUMANA: ANÁLISIS CRÍTICO DE LAS PROPUESTAS DESPERSONALIZADORAS Y DESPENALIZADORAS}

desconocer la importancia de estos últimos y la necesidad de darles respuestas adecuadas 99 .

En este punto, llama la atención cierta incoherencia en algunas concepciones morales y jurídicas actuales: el término "persona" es aplicado por cierta doctrina y jurisprudencia a algunos animales con el objeto de reconocerles ciertos derechos (se habla incluso de personas no humanas) ${ }^{100}$. De ese modo, se procura que una entidad vital "no humana" reciba la protección jurídica -reconocimiento de derechos- en calidad de persona. $\mathrm{Y}$, en contraste, se discute la calidad de persona de la entidad vital "ser humano".

En consecuencia, nos vemos impelidos racionalmente a buscar argumentos éticos dirigidos a reconocer el valor de la vida humana del no nacido incluso frente a la autonomía de la mujer, pues la postura que niega tal dignidad con invocación de la "falacia naturalista"101 deja sin protección la vida humana hasta el nacimiento, o termina aceptando, a la postre, una protección insuficiente por establecer plazos con criterios discutibles, subjetivos y relativos (a pesar del intento de un objetivismo mínimo por parte de autores como Vázquez).

Todas estas posturas, en definitiva, permiten justificar el aborto hasta el nacimiento o por un plazo determinado por cualquier motivo: por razones médica, ética, eugénica y socioeconómica ${ }^{102}$.

Por todo ello, la adopción de una posición moral o ética adecuada debe encaminarse a la defensa de la vida humana desde su inicio, lo que derivará en la

\footnotetext{
99 En nuestro país, el proyecto de despenalización del aborto, tratado en el Congreso de la Nación, tuvo en paralelo otros proyectos no tratados dirigidos a evitar, precisamente, los daños derivados de la prohibición del aborto. Véase, por ejemplo, el Proyecto de ley de régimen de protección integral de los derechos humanos de la mujer embarazada y de los niños por nacer. Expediente Diputados: 0324-D-2018. Firmado por 33 diputados. Entre otros proyectos en ese sentido que pueden verse en: https://maternidadvulnerable.com.ar/2018/og/10/proyectos-de-ley-para-cuidar-las-dos-vidas/ 100 Cf. AA.VV., El Derecho de los animales, Baltasar, Basilio (coordinador), Marcial Pons, Ediciones Jurídicas y Sociales, Madrid, 2015.

${ }^{101}$ Debe señalarse que la llamada "falacia naturalista", conocida como "ley de Hume", y explicitada por George Edward Moore (Principia Ethica, traducción castellana de A. García Díaz, México, Unam, 1959), es discutida por algunos filósofos del derecho ubicados en una vertiente iusnaturalista: cf MASSINI-CORREAS, Carlos l. "La falacia de la "falacia naturalista"". Persona y Derecho, 29 (1993), pp. 47-95.

${ }^{102}$ Ver los distintos sistemas en BUOMPADRE, obra citada, p. 200.
} 


\section{EL ABORTO Y LA DIGNIDAD DE LA VIDA HUMANA: \\ ANÁLISIS CRÍTICO DE LAS PROPUESTAS \\ DESPERSONALIZADORAS Y DESPENALIZADORAS}

justificación de la penalización del aborto. Y esa posición moral o ética puede centrarse en los principios de la razón práctica, desde la perspectiva de un neoiusnaturalismo como el sostenido por Finnis.

Desde este punto de vista, no puede desconocerse que el aborto produce, como consecuencia dañosa, la muerte de un ser humano concebido, de modo que esa eliminación definitiva, sin posibilidad alguna de reparación, de una vida humana inicial, aparece como una conducta moralmente indebida y el castigo del aborto se encontrará justificado. No otra consecuencia debe derivarse de la sacralidad de la vida humana que destaca Dworkin.

En la concepción de Michael Moore, tenemos razones morales para criminalizar las acciones dañosas porque, y en la medida en que, tenemos obligaciones morales de no producir esos daños; esas razones morales dan las razones para criminalizar ${ }^{103}$. Y ello es así, agregamos, cuando el daño es irreversible, como sucede con la eliminación de la vida humana.

Si esas razones morales derivan de un derecho natural es algo que aquí no vamos a analizar en profundidad porque excede los límites del presente estudio. Pero parece evidente que a causa del rechazo del derecho natural la moral queda reducida a un asunto meramente subjetivo de conciencia individual, y el derecho tiende a ser funcionalizado utilitariamente como puro instrumento de gestión técnica de las relaciones sociales. Con otras palabras, ese rechazo deriva en una moral subjetivista reducida a un asunto meramente individual, y en un derecho positivista que se expresa en leyes interpretativas de la voluntad de la mayoría y legitima conductas inseguras en lo moral104.

103 MOORE, Michael, Placing Blame. A Theory of Criminal Law, Oxford University Press, Oxford, 1997, citado por FERRANTE, Marcelo, "Filosofía del Derecho Penal", en Manual del Teoría y Filosofía del Derecho, vol III, Fabra Zamora, Jorge Luis Spector, Ezequiel Coordinadores, Instituto de Investigaciones Jurídicas de la UNAM, pp. 2100/2101.

104 CASAS, Gustavo, Antropología Filosófica. Orientaciones para un curso, Editorial de la Universidad Católica de Córdoba, Córdoba, 2003, pp. 258/260. El autor, fallecido en el año 2014, fue un humilde sacerdote jesuita y profesor de Antropología Filosófica de la Facultad de Derecho de la Universidad Católica de Córdoba, Argentina. 


\section{EL ABORTO Y LA DIGNIDAD DE LA VIDA HUMANA: ANÁLISIS CRÍTICO DE LAS PROPUESTAS DESPERSONALIZADORAS Y DESPENALIZADORAS}

Ese parece ser el gran defecto de las posturas morales analizadas ${ }^{105}$ : el principio de laicidad del derecho y de la moral llega al extremo inaceptable de justificar la eliminación deliberada de un ser humano inocente simplemente porque no es deseado por la madre, y mientras no adquiera las facultades de pensar o sentir prevalece la libertad de conciencia o la autonomía de aquella. De ese modo, la moral queda reducida a un asunto meramente subjetivo de conciencia individual.

Esos son los resultados inevitables de la objeción filosófica conocida como "falacia naturalista”, en tanto impide todo tipo de ética objetiva y niega la tesis central del derecho natural. Por esos motivos, esa "falacia" presenta resistencias en el ámbito de la filosofía moral ${ }^{106}$.

105 En el mismo sentido, la argumentación del filósofo Gustavo ORTIZ MILLÁN, del Instituto de Investigaciones Filosóficas de la UNAM, en su libro La moralidad del aborto, Siglo XXI, México, 2009, intenta también brindar una visión superadora de las posturas de conservadores y liberales. En ese sentido, explica que para el conservador extremo, la premisa principal es que el cigoto es un ser humano completo desde el momento de la concepción y que tiene un "superderecho" a la vida que derrotaría a cualquier otro derecho con el que entrara en conflicto (p. 20), y sólo sería permisible el aborto (terapéutico) cuando está en riesgo la vida de la madre (p. 22), y en su versión moderada suele aceptar también el eugenésico (malformaciones congénitas) y por violación. Mientras que para la posición liberal extrema es central el mayor valor del derecho de la mujer a decidir sobre su propio cuerpo, sobre su plan de vida, y realizarlo. Este derecho se asocia con otros, tales como privacidad, integridad corporal, dignidad, igualdad, no discriminación por razón de género, libre desarrollo personal, sexualidad y de reproducción (p. 27). Tales derechos -según la posición liberal extrema- deben prevalecer porque son los derechos de una persona nacida y no de una persona potencial; por lo tanto, se niega que sea aceptable atribuir derechos al feto. Además, esta posición utiliza argumentos basados en las consecuencias que se siguen de considerar ilegal el aborto: por ejemplo, fuertes índices de morbi-mortalidad materna; por lo tanto, el aborto es también (o primordialmente) un problema de "salud pública", de derecho a la salud que debe garantizárseles a las mujeres (p. 29). Ante tales posturas, adopta una posición similar a la de los filósofos tratados en este trabajo: el embrión o feto no es persona al menos hasta los tres meses; la personalidad como centro de imputación de derechos no depende del código genético ni de que pertenezca al género homo sapiens, sino de predicados psicológicos básicos como la autopercepción de placer y dolor; el embrión o feto, durante ese primer tiempo, no es persona como sí es la madre; ergo, la penalización del aborto en el primer trimestre es inmoral porque viola derechos sobre la base de un concepto erróneo de persona y conlleva consecuencias negativas en términos de salud social. Puede verse una reseña de esa obra en Diánoia vol.55 no.64 México may. 2010, disponible en línea: http://www.scielo.org.mx/scielo.php?script=sci arttext\&pid=S0185-24502010000100011

106 Además del trabajo de MASSINI-CORREAS, ya referido en notas anteriores, existen otras posturas críticas hacia la "falacia naturalista" en cuanto negadora de toda concepción objetivista de la ética. Por caso, la de John Finnis, quien acepta que el paso del ser al deber ser es indebido, y que de la naturaleza humana no pueden derivarse principios básicos para la acción, pero postula la noción de bienes humanos básicos que se presentan de manera inmediata y autoevidente a la conciencia humana. De modo que lo moralmente correcto será lo moralmente razonable en orden a la consecución o preservación de un bien. Hay entonces bienes premorales, bienes humanos 


\section{EL ABORTO Y LA DIGNIDAD DE LA VIDA HUMANA: \\ ANÁLISIS CRÍTICO DE LAS PROPUESTAS \\ DESPERSONALIZADORAS Y DESPENALIZADORAS}

Acaso el camino más acorde con el respeto de la dignidad humana pase por aceptar que existen bienes humanos básicos autoevidentes (o sea indemostrables) y autónomos (es decir, no hay bienes que sean instrumentos de otros), como lo es la vida. Y de esa manera reconocer -como postula Finnis- que a partir de ellos la inteligencia humana puede discernir lo que es bueno y debe ser perseguido, y ello es lo que permite fijar cursos de acción o tomar decisiones ${ }^{107}$.

Y ese discernimiento impele a proteger la vida humana incluso en su estadio inicial, pues lo contrario supondría su instrumentalización para otros fines y desconocer, de ese modo, su dignidad.

El desarrollo de esa posición, que sin negar la ley de Hume -no se pueden derivar juicios de valor de juicios de hecho- reconoce la existencia de un derecho natural, demanda un estudio más exhaustivo que excede los fines de este trabajo.

Este principio de razonamiento práctico, en definitiva, parece ser un parámetro razonable para analizar moralmente la muerte deliberada del ser humano en gestación, desde una perspectiva de derecho natural y desde una postura ética objetiva.

\section{Conclusiones}

Hemos intentado indagar acerca del bien jurídico protegido en la figura penal del aborto, o, más precisamente, si hay un bien jurídico que deba ser protegido por el derecho penal de manera eficaz, sin perjuicio de la posible colisión con otros derechos, en particular los de las mujeres.

básicos, como son la vida, el conocimiento de la verdad, el juego, la experiencia estética, la sociabilidad o amistad, la razonabilidad práctica. Estos bienes son autoevidentes, autónomos y sin diferencias de jerarquía entre ellos. Y aquí aparece el principio de la razonabilidad práctica: la razón humana capta esos bienes básicos, y la moralidad aparece cuando el hombre persigue esos bienes en sus concretas decisiones y acciones. Pueden verse estos conceptos desarrollados en SALDAÑA SERRANO, Javier, "La falacia naturalista. Respuestas para una fundamentación del derecho natural. Los argumentos de J. FINNIS y M. BEUCHOT”, Anuario de Filosofía y Teoría del Derecho, UNAM, 2007, pp. 419/447.

107 Puede verse: FINNIS, John, Estudios de Teoría del Derecho Natural, UNAM, Instituto de Investigaciones Jurídicas, México, 2017. 
EL ABORTO Y LA DIGNIDAD DE LA VIDA HUMANA:

ANÁLISIS CRÍTICO DE LAS PROPUESTAS

DESPERSONALIZADORAS Y DESPENALIZADORAS

La inconsistencia de las posturas éticas subjetivistas que hemos analizado, en cuanto llevan a despersonalizar la vida humana inicial y a desconocer su dignidad, nos llevan a reflexionar sobre la necesidad de reconocer un bien jurídico que no quede vacío de su significado y trascendencia. Esto es, que reconozca la dignidad de la vida humana en cualquier etapa de su desarrollo (en su inicio y en su final), y que de ese modo el Estado deba intervenir, incluso con el derecho penal, contra las acciones que atentan contra ella ${ }^{108}$.

Ello es imprescindible frente a las premisas filosóficas utilizadas para justificar la despenalización del aborto, las que en la práctica llevan a un debilitamiento de la vida humana en general, y pueden llevar a justificar otros ataques al carácter sagrado de la vida humana, como el infanticidio y la eutanasia.

Por lo demás, si la vida humana, incluso la inicial, tiene la dignidad que la hace merecedora de protección, los daños que ocasionan los embarazos no deseados ${ }^{109}$

108 De lo contrario, sin ese fundamento primigenio, pueden llegarse a soluciones jurídicas aberrantes, como considerar que el embrión no es un ser humano y, por ello, su eliminación es una autolesión no punible. Véase, en ese sentido, el voto en minoría del juez Magariños en el reciente fallo de la Cámara Nacional en lo Criminal y Correccional de la Capital Federal, Sala 3, en la causa "C.P.C. s/violación según párrafo 4to art. 119 inc. b, etc". Los jueces integrantes de la mayoría, Huarte Petite y Jantus, consideraron que en la sentencia se tuvo por probado de modo incorrecto que el embrión se encontrase con vida antes del ejercicio de la práctica dirigida a interrumpir el embarazo y, sobre esa base, entendieron que ese hecho constituía un supuesto de "tentativa inidónea por el objeto", razón por la cual resultaba atípico. Pero el voto en minoría del juez Magariños, como ya referimos, afirma que la eliminación de un embrión sin viabilidad extrauterina -en el caso, de nueve semanas- no es aborto sino autolesión no punible (propio cuerpo de la madre), y su castigo vulneraría el art. $19 \mathrm{CN}$. Un voto muy fundamentado con doctrina jurídica y "científica-no jurídica". Un tratado, podría decirse. Opta por una posición científica (la expuesta por Kornblihtt en el marco de la discusión sobre el aborto, acerca de que el embrión no es un ser humano) y acomoda a ella toda su interpretación convencional, constitucional y penal. Ello es demostrativo de los extremos a los que puede llevar la discusión sobre los conceptos de vida humana y de persona, y las consecuencias que tendrá la adopción de una posición ética o, incluso, científica, en las consideraciones jurídicas que puedan realizarse sobre el aborto.

109 Tales daños han sido un argumento recurrente en las discusiones parlamentarias del año 2018. Por ejemplo, el entonces Ministro de Salud de la Nación, Adolfo Rubinstein, quien participó el 31 de mayo de 2018 en la decimoquinta jornada de debate por la legalización del Aborto en Argentina, en el $15^{\circ}$ plenario de comisiones del Congreso de la Nación: "Es un problema de salud pública, porque el aborto produce muertes, morbilidad evitable en población joven y sana; es un problema de equidad de género, porque el aborto sólo afecta a las mujeres y adolescentes y sus complicaciones afectan sobre todo y fundamentalmente a las mujeres pobres; porque los países con marcos legales restrictivos no han reducido el número de abortos sino que han aumentado la proporción de abortos inseguros; y finalmente porque la evidencia es muy robusta, sólida, respecto a que la despenalización del aborto reduce la mortalidad materna, las complicaciones graves y el número de abortos totales". 
pueden ser contrarrestados con la promoción de medidas de acción positiva en favor de las madres, especialmente las de mayor vulnerabilidad, y de sus hijos por nacer ${ }^{110}$.

Con otras palabras, la idea de no instrumentalización de la mujer no ha de olvidar la idea de no instrumentalización del ser humano gestado, sin perjuicio de la dependencia biológica de este último al cuerpo de la madre.

No parece, en definitiva, que desde una concepción subjetivista de la ética pueda surgir una posición moral y una postura jurídico-política que reconozcan debidamente la dignidad de la vida humana y resuelvan adecuadamente los problemas ocasionados a las mujeres por los embarazos "no deseados". Acaso ello sólo sea posible a partir de una postura filosófica que parta del reconocimiento de una ley moral natural.

Queda pendiente un estudio más profundo de esa propuesta, para la cual este trabajo constituye sólo el primer esbozo.

\section{Bibliografía}

BUOMPADRE, Jorge Eduardo, Tratado de Derecho Penal. Parte Especial, $3^{\text {a }}$ edición actualizada y ampliada, Astrea, Buenos Aires, 2009, T. I.

CASAS, Gustavo, Antropología Filosófica. Orientaciones para un curso, Editorial de la Universidad Católica de Córdoba, Córdoba, 2003.

CORRAL TALCIANI, Hernán F. - VIGO PACHECO, Alejandro Gustavo, Revista chilena de derecho, Vol. 21, $\mathrm{N}^{\circ}$ 2, 1994.

DE LA RÚA, Jorge - Tarditti, Aída, Derecho Penal Parte General, Hammurabi, Buenos Aires, 2014, T. 1.

DONNA, Edgardo Alberto, Derecho Penal. Parte Especial, $4^{\text {a }}$ edición actualizada, Rubinzal-Culzoni, Santa Fe, 2001, T. I.

DWORKIN, Ronald, El dominio de la vida. Una discusión acerca del aborto, la eutanasia y la libertad individual, traducción de Ricardo Caracciolo y Víctor Ferreres, Barcelona, Ariel, 1994.

FAVAROTTO, Ricardo Silvio - Juliano, Mario Alberto, "El bien jurídico", en Temas de Derecho Penal Argentino, La Ley, Buenos Aires, 2006.

${ }^{110}$ Ya nos hemos referido más arriba, en nota a pie de página, a los distintos proyectos presentados en el Congreso de la Nación en ese sentido. 
FERRANTE, Marcelo, "Filosofía del Derecho Penal”, en Manual del Teoría y Filosofía del Derecho, vol III, Fabra Zamora, Jorge Luis Spector, Ezequiel Coordinadores, Instituto de Investigaciones Jurídicas de la UNAM.

FINNIS, John, Estudios de Teoría del Derecho Natural, UNAM, Instituto de Investigaciones Jurídicas, México, 2017.

KEMMELMAJER de Carlucci, Aída, "Legalización del aborto y derecho a la vida. Consideraciones jurídicas", en Semanario Jurídico, Número 2189, 31/1/2019, Cuadernillo 2, Tomo 119, Año 2019 - A.

MASSINI-CORREAS, Carlos I. "Estudio preliminar a John Finnis: Teoría del derecho natural", en FINNIS, John, Estudios de Teoría del Derecho Natural, UNAM, Instituto de Investigaciones Jurídicas, México, 2017.

MASSINI-CORREAS, Carlos I. "La falacia de la 'falacia naturalista'". Persona y Derecho, 29 (1993).

MASSINI CORREAS, Carlos I., "Sobre el embrión humano y la cuestión de la personalidad. Un argumento de Luigi Ferrajoli y su discusión”, en Prudentia Iuris, $\mathrm{N}^{\circ} 76,2013$.

MIR PUIG, Derecho Penal Parte General, 9ª edición, B de F, Buenos Aires, 2011.

ORTIZ MILLÁN, Gustavo La moralidad del aborto, Siglo XXI, México, 2009

ROXIN, Derecho Penal Parte General, Civitas, Madrid, 1997, 2º Reimpresión, Thomson Reuters, Buenos Aires, 2015, T. I.

RUIZ MIGUEL, Alfonso, "El aborto, entre la ética y el Derecho", en Telos, Revista Iberoamericana de Estudios Utilitaristas, 2002, XI/2.

SALDAÑA SERRANO, Javier, "La falacia naturalista. Respuestas para una fundamentación del derecho natural. Los argumentos de J. Finnis y M. Beuchot”, Anuario de Filosofía y Teoría del Derecho, UNAM, 2007

SILVA SÁNCHEZ, Jesús María, La expansión del derecho penal. Aspectos de la política criminal en las sociedades postindustriales, $2^{\mathrm{a}}$ ed., Civitas, Madrid, 2001.

VÁZQUEZ, Rodolfo, "Comentarios a las propuestas bioético-jurídicas de Luigi Ferrajoli”, en Garantismo. Estudios sobre el pensamiento jurídico de Luigi Ferrajoli, Edición de Miguel Carbonell y Pedro Salazar, Editorial Trotta, Instituto de Investigaciones Jurídicas - UNAM, Madrid, 2005,

VON LISZT, Franz, Tratado de Derecho Penal, Reus, Madrid, 1916. 